\title{
EL RENACER DE LAS TEORÍAS DE LA IMPUTACIÓN EN LA DOGMÁTICA JURÍDICO-PENAL: ¿HACIA UNA ETAPA SUPERADORA O INVOLUCIÓN A CONCEPCIONES PRE-CIENTÍFICAS?*
}

Nicolás Santiago Cordini**

\begin{abstract}
Resumen: La ciencia del Derecho penal atraviesa un momento que puede ser caracterizado como de 'crisis'. Ante dicha situación, han proliferado teorías que se definen a sí mismas como "teorías de la imputación" que abandona, total o parcialmente, la teoría del delito hasta ahora dominante. La finalidad del presente artículo es analizar tres teorías enroladas bajo el concepto de imputación y determinar en qué medida conservan o se alejan de las categorías propuestas por la teoría del delito. Paso siguiente, estableceremos en qué medida estas teorías constituyen un avance para la ciencia
\end{abstract}

El presente trabajo ha sido realizado en el marco de un Doctorado Sandwich Erasmus en el Departamento de Derecho Penal de la Georg-August Universität Göttingen - Alemania.

** Doctor en Derecho, Investigador y Profesor de Derecho penal I, Facultad de Ciencias Jurídicas y Sociales - Universidad Nacional del Litoral, Centro de Investigaciones de la FCJslunL, Cándido Pujato 2751, Santa Fe, CP 3000, Argentina. Correo-e: ncordini@fcjs.unl.edu.ar. Santa Fe, Argentina. Fecha de recepción: 20 de marzo de 2015. Fecha de modificación: 6 de julio de 2015. Fecha de aprobación: 30 de julio de 2015. Para citar el artículo: Nicolás SAnTiago Cordini (2015). "El renacer de las teorías de la imputación en la dogmática jurídico-penal: ¿hacia una etapa superadora o involución a concepciones pre-científicas?”, en Revista Derecho Penal y Criminología, Vol. 36, n. ${ }^{\circ}$ 100, enero-junio de 2015. Bogotá: Universidad Externado de Colombia, pp. 89-123. DOI: http://dx.doi.org/10.18601/ 01210483.v36n100.06 
del Derecho penal o, por el contrario, son manifestaciones de un retroceso a etapas pre-científicas.

Palabras clave: Imputación; Derecho penal; Avance; Retroceso.

\title{
THE REBIRTH OF THE THEORY OF IMPUTATION IN THE SCIENCE OF CRIMINAL LAW: TO AN OVERCOMING STAGE OR AN INVOLUTION TO PRE-SCIENTIFIC CONCEPTIONS?
}

\begin{abstract}
The Science of Criminal Law goes through a moment that can be characterized as a "crisis". Faced with this situation, have been proliferated theories that define themselves as "theories of imputation" that leave, in whole or in part, the theory of crime up to now dominating. The aim of this article is to analyze three theories enrolled under the concept of imputation and determine in which proportion they conserve other they get off the categories proposed by the theory of crime. Then, we will establish in which proportion these theories constitute an advance for the Science of Criminal Law or, on the contrary, they are manifestations of a retreat to a pre-scientific stage.
\end{abstract}

Keywords: Imputation; Criminal Law; Advance; Retreat.

\section{INTRODUCCIÓN}

El momento actual de la dogmática jurídico-penal puede ser caracterizado como de 'crisis', dada la convivencia desordenada de diversos métodos y puntos de vista valorativos, modas de argumentación y perspectivas de análisis. La imagen de las diversas concepciones filosóficas, argumentos, métodos y perspectivas de análisis que se solapan en un determinado ámbito de problemas conforman el "eclecticismo" actual que atraviesa esta disciplina ${ }^{1}$. No es de extrañar que en un campo científico ${ }^{2}$

1 Cuando utilizamos el término "disciplina" seguimos el concepto establecido por WALLERSTEIN que refiere, en realidad, a tres cosas al mismo tiempo. "En primer lugar, a categorías intelectuales, modos de afirmar que existe un campo de estudio definido con algo parecido a límites, aunque sean controvertidos o borrosos, y con modalidades de investigación separadas como legítimas. En este sentido, las disciplinas son constructos sociales (...). En segundo lugar, las disciplinas son estructuras institucionales que han ido adaptando una forma cada vez más elaborada desde el siglo XIX. Las universidades se dividen en departamentos que llevan nombres disciplinares, los títulos universitarios corresponden a disciplinas específicas y los profesores tienen cargos que también comprenden el nombre de la disciplina a la que se dedican (...). Por último, las disciplinas son también una cultura. Habitualmente, los académicos que dicen pertenecer a un grupo disciplinar comparten con los otros miembros del grupo experiencias y contactos: han leído los mismos textos 'clásicos'; participan de los mismos debates tradicionales, que a menudo son distintos de los de las disciplinas lindantes; tienen un mismo estilo y reciben recompensas por ello" (WALLERSTEIN, 2005: 141-142).

2 Cuando utilizamos el concepto de "campo científico" seguimos a PIERRE BourdiEU, quien lo define de la siguiente manera: "El campo científico como sistema de relaciones objetivas entre las posiciones adquiridas (por las luchas anteriores) es el lugar (es decir, el espacio de juego) de una lucha de 
convulsionado proliferen teorías que se definan a sí mismas como "teorías de la imputación" abandonando, total o parcialmente, la teoría del delito hasta ahora dominante.

Además del eclecticismo vigente se suman otros factores, tanto endógenos como exógenos a la disciplina penal, que acentúan su situación de crisis. Entre los primeros podemos mencionar el hecho de que la teoría del delito en cuanto objeto de análisis posee carácter instrumental, lo que limita las investigaciones estrictamente dogmáticas que se pueden hacer sobre ella. Todo aquel concepto que no quepa dentro de la última categoría representada por la culpabilidad, constituye harina de otro costal, siendo una problemática ajena a la teoría. Ante una suerte de agotamiento de los temas de discusión, las soluciones han tomado diversas vías. La primera podríamos calificarla como "corrimiento disciplinario"; en un afán por encontrar un nicho de investigación, los penalistas han optado por trasladar los temas de discusión a una meta-dimensión, dejando de ser discusiones exclusivamente penales para transformarse en una "Epistemología del Derecho penal". Las modernas "teorías de la imputación" se enrolan en esta solución, puesto que la adopción de uno de estos modelos de comprensión conlleva un cambio de perspectiva a la hora de analizar el hecho delictivo. Para la teoría del delito, un delito es el producto de la aplicación de categorías legales mediante una operación de comprobación y subsunción. Para las teorías de la imputación, por el contario, esta es un medio de atribución de sentido y de consideración del sujeto al que se atribuye responsabilidad, al que se imputa. La segunda de las vías es la alternativa de ampliar la teoría del delito a categorías que se encuentran más allá de la culpabilidad, esto es, repensar una teoría que incluya todos aquellos presupuestos que deben ser tenidos en cuenta, desde la comisión del delito hasta la efectiva aplicación de pena ${ }^{3}$.

Entre los factores exógenos podemos mencionar la ampliación del sistema universitario, lo que trajo como consecuencia un aumento pronunciado de investigadores que luchan por encontrar su nicho de investigación sobre un objeto ya de por sí escaso $^{4}$, produciendo cambios en las condiciones de reclutamiento y formación de

competencia que tiene por desafío específico el monopolio de la autoridad científica, inseparablemente definido como la capacidad técnica y como el poder social, o si se prefiere, el monopolio de la competencia científica, entendida en el sentido de la capacidad de hablar y actuar legítimamente (es decir, de manera autorizada y con autoridad) en materia de ciencia, que es socialmente reconocida a un agente determinado" (Bourdieu, 1975: 91-92). Las traducciones del inglés, del alemán y del francés al español son de nuestra autoría, salvo que se indique lo contrario.

3 Wolter (1996: 1-42), en su intento de elaborar un sistema integral del Derecho penal (gesamtes Strafrechtssystem), propone la elaboración de un sistema que integre tres perspectivas: la del Derecho penal material, la del Derecho procesal penal y la de la determinación de la pena.

4 En palabras de WALLERSTEIN (1996: 39), "La expansión desenfrenada de los sistemas universitarios en el mundo entero tuvo una implicación organizacional muy concreta: creó una presión social por el aumento de la especialización debido simplemente al hecho de que los estudiosos buscaban nichos que pudieran definir su originalidad o por lo menos su utilidad social. El efecto más inmediato consistió en estimular las intrusiones recíprocas de científicos sociales en campos disciplinarios vecinos, 
científicos dentro del campo penal ${ }^{5}$. El aumento de investigadores que tratan de definir su nicho de investigación en el ámbito de una disciplina cuyo objeto es, como ya se mencionó supra, de por sí limitado, trae como consecuencia un corrimiento disciplinario, produciendo un cambio parcial no solo en el objeto de estudio, sino que dicho desplazamiento alcanza también al método y a la perspectiva epistemológica. Otro de los factores exógenos a la dogmática jurídico-penal es el cambio de modelo de sociedad, en términos de BECK, el tránsito de una sociedad moderna a un modelo diverso caracterizado como "sociedad del riesgo" (Risikogesellschaft). Este modelo de sociedad se define a partir de estar signada por la lógica de la distribución de riesgos, del mismo modo que el conflicto central de la sociedad industrial giraba en torno a la distribución de las riquezas ${ }^{6}$. La sociedad del riesgo produce, al interior del Derecho penal, la pretensión de transformar las estructuras básicas del mismo de acuerdo con las nuevas necesidades sociales que demanda este modelo social, lo que se traduce en un uso simbólico del Derecho penal legitimado por el discurso preventivo-general desde una perspectiva funcionalista. En la sociedad del riesgo, la disminución de los espacios de riesgo permitido es consecuencia de una sobrevaloración de la seguridad frente la libertad. En términos de SiLVA SÁnCHEZ (2006: 37), "nos hallamos en un modelo de sociedad orientado a una restricción progresiva de las esferas de actuación arriesgada. En otras palabas (...), en la ponderación previa al establecimiento de las fronteras entre riesgo permitido y riesgo desaprobado, la libertad de acción ha cedido con claridad frente a la libertad de no pasión". No solo se reducen las esferas de libertad, sino que, al mismo tiempo, hay un rechazo a considerar sucesos como meramente accidentales, es decir, se niega la imputación a la víctima a título de 'desgracia', ante la imposibilidad de atribuir el hecho al autor o a un tercero. Ante la negativa a que el suceso no pueda ser imputado a persona alguna, se produce una despersonalización y una a-moralización del proceso imputativo (SILVA SÁNCHEZ, Op. cit.: 42).

Al positivismo, como fruto específicamente moderno, le debemos no solo el método científico sino también la idea de "progreso", constituyendo este un proceso sin fin y a cuyas etapas precedentes no resulta posible retornar. Sin embargo, el hecho de que estas teorías produzcan el resurgir de modelos inspirados en teorías precientíficas nos lleva a indagarnos si la dogmática jurídico-penal se enfrenta a modelos superadores o si, por el contrario, ellas manifiestan un retorno a etapas que se creían ya superadas.

ignorando en este proceso las varias legitimaciones que cada una de las ciencias sociales había erigido para justificar sus especificidades como reinos reservados. Y la expansión económica alimentó esa especialización proporcionando recursos que la hicieron posible".

5 Para mayor ahondamiento, véase SchünEMANN (1995: 201-229).

6 En la modernidad avanzada, la producción social de riqueza va acompañada sistemáticamente por la producción social de riesgos. Por tanto, los sistemas y conflictos de reparto de la sociedad de la carencia son sustituidos por los problemas y conflictos que surgen de la producción, definición y reparto de los riesgos producidos de manera científico-técnica (BECK, 1998: 25). 


\section{LA IMPUTACIÓN: UN MODO DE COMPRENDER EL MUNDO}

La atribución de un hecho a un sujeto como su obra, es decir, la imputación, es anterior a la explicación del fenómeno en términos causales. Aun antes de que la ley de la causalidad fuese descubierta, ya se imputaban hechos a las personas como suyos. Tanto los actos objeto de alabanza eran recompensados, como sancionados los actos objeto de reproche, y para ello no se requería establecer la relación entre la causa y el efecto. El principio de imputación era el modo que utilizaban las sociedades primitivas para comprender el mundo. No solo recurrían a este modo de comprensión para explicar sus relaciones sociales (KELSEN, 1960: 86), sino que la manera como concebían dichas relaciones servía para explicar los fenómenos naturales, constituyendo una interpretación socio-normativa de la naturaleza, en la cual el pensamiento causal no formaba parte de esta manera de comprender el mundo ${ }^{7}$.

La existencia de una dualidad entre un orden causal y un orden normativo solo es posible a partir de la emancipación del hombre respecto de las cosas, de un desencantamiento del mundo como obra del proyecto moderno; proceso de emancipación que duró varios siglos y cuya culminación marca el nacimiento de la modernidad. La separación entre mundo natural y mundo social no solo implicó el nacimiento del humanismo sino también el nacimiento conjunto de la "no humanidad", constituido por las cosas, los objetos, los animales y el Dios tachado, fuera de juego (LATOUR, 2007: 33). A partir de esta división es posible instituir un orden natural, regido por la ley de la causalidad, y un orden social, regido por el principio de imputación.

El primer análisis de la imputación en el ámbito de la filosofía se encuentra en $L a$ ética nicomáquea de Aristóteles, concepto que siguió siendo estudiado tanto desde la filosofía aristotélico-tomista, como desde el racionalismo, con autores como SAMUEL PUFENDORFO CHRISTIAN WOLFF, pasando por el idealismo alemán con IMMANUEL KANT y Georg Wilhelm Friedrich Hegel. Los aportes hechos por el racionalismo y el idealismo han imbuido a la doctrina penal de conceptos, categorías, principios, etc., cuyo objetivo ha sido siempre el de dotar al Derecho penal de una mayor racionalidad a la hora de resolver conflictos. Uno de esos conceptos, o para ser más exactos, una de las teorías que ha desarrollado la filosofía penal de aquel período, fue la de la imputación (die Zurechnungslehre). Sin embargo, este modo de comprender el

7 "La idea que los eventos están determinados por la ley de la naturaleza, el concepto del principio de causalidad (...) está totalmente más allá del alcance del hombre primitivo. Se puede hablar de 'pensamiento causal' sólo si la regularidad percibida en toda sucesión de eventos es también considerada necesaria. Pero precisamente esta cadena regular de eventos, por la cual el comportamiento del hombre primitivo es actualmente guiado y de la cual él depende en sus acciones y omisiones, no le da ninguna causa para la reflexión: como un chico, él acepta la cadena de eventos sin pensar sobre ella" (KELSEN, 1943: 3). 
delito fue dejado de lado por la dogmática jurídico-penal que se instaura a partir del positivismo $\mathrm{y}^{8}$, con ella, el concepto de imputación fue abandonado.

El proyecto positivista se extendió a todas las ciencias sociales, no siendo la dogmática jurídico-penal ajena a este fenómeno. Esta filosofía consistía en estatuir al principio de causalidad como instrumento idóneo para comprender el mundo. Cuando el positivismo se estableció como movimiento dominante en la segunda parte del siglo XIX, hacía ya tiempo que la ciencia penal alemana utilizaba el método dogmático. Por otra parte, tampoco en Alemania llevó el positivismo a reclamar la realidad empírica naturalística como objeto de la ciencia jurídico-penal, sino que la misma siguió definiendo al Derecho positivo como el objeto de su disciplina ${ }^{9}$. El delito, conforme a este punto de vista epistemológico, se define como el hecho contrario a la norma del Derecho vigente atribuible a la culpabilidad, conminado en la ley antes de su realización con una pena. Pero a los fines del injusto, el delito no se agota en verificar la contradicción de la norma, sino que requiere que el sujeto sea susceptible de imputación. De esta manera, el concepto de imputación queda reducido como capacidad de imputabilidad (Zurechnungsfähigkeit), a la capacidad de motivación.

La mayor herencia que ha dejado la dogmática jurídico-penal positivista ha sido la teoría del delito, cuyas categorías de análisis, si bien han sido dotadas de contenido diverso con el transcurrir de distintas corrientes del pensamiento, se han mantenido hasta la actualidad. En ese transcurso, sin embargo, se han alzado voces detractoras de ella en cuanto modo de comprensión, propugnando una vuelta a la idea de imputación ${ }^{10}$, aunque sin demasiada repercusión en el campo científico. No obstante, a partir del último tercio del siglo pasado, han proliferado en la dogmática jurídico-penal alemana diversas teorías, que, si bien son minoritarias, adoptan la perspectiva de la imputación, siendo necesario determinar qué tienen en común estos modelos teóricos.

8 Según la concepción del positivismo, no existe ninguna diferencia de principio entre el enlace causal en la naturaleza inanimada, en los procesos orgánicos de desarrollo, y la determinación psíquica, la motivación. En todas partes rige el principio de que todo cambio perceptible en el tiempo ha de tener su causa precedente en el tiempo, la cual, a su vez, tiene como consecuencia, necesariamente, conforme a las leyes de la naturaleza, el efecto (LARENZ, 1974: 53).

9 En Alemania no se llegó a sustituir el objeto tradicional de la dogmática jurídico-penal, el Derecho positivo, por la realidad empírica. El estudio experimental del fenómeno criminal se añadió a la dogmática jurídico-penal como parte diferenciada de la total ciencia penal (gesamte Strafrechtswissenschaft). En la dogmática el naturalismo influyó solo en cuanto al modo de estudio del derecho positivo, que siguió constituyendo su único objeto (MIR PUIG, 2003: 197-198).

10 Ya a mediados del siglo Xx, WERNER HARDWIG (1957) presentó un modelo teórico alternativo a la teoría del delito, defendiendo una teoría de la imputación. Sin embargo, el concepto de imputación ya había sido reintroducido con anterioridad en la dogmática jurídico-penal y no es casual que fuese de la mano de un autor de origen neokantiano, como lo fue RICHARD HoNIG (1930: 174-201); sin embargo, esta reintroducción del concepto de imputación, ahora con el aditamento "objetiva", no se condice con el concepto de imputación utilizado por las doctrinas pre-científicas. 


\section{LAS TEORÍAS DE LA IMPUTACIÓN: DIVERSOS MODELOS}

Cuando hablamos de las teorías de la imputación, del concepto de imputación en sentido amplio, o bien, de un sistema de imputación total, estamos aludiendo a un concepto que no se circunscribe a la determinación de los resultados atribuibles al sujeto, esto es, la imputación objetiva del resultado, sino que comprende al delito como una totalidad. A saber, a la atribución del injusto culpable. Para estos modelos, es materia de imputación tanto la atribución del hecho ilícito como también la atribución del hecho desvalorado al agente como culpable.

Conforme al concepto amplio de imputación, esta debe ser entendida como un juicio mediante el cual un determinado suceso, sea un movimiento corporal o un sonido, es considerado un hecho, o sea, una acción del artífice (Urheber). Acción que es atribuida nuevamente al sujeto como culpable, en la medida que el actor no haya seguido el deber que la norma le imponía. Modelos de imputación total son los propuestos por WERnER HARDWIG, JOACHIM HRUSCHKA, y autores afines, como UlFRID NEUMANN y JAN C. JoERden, GÜNTHER JAKOBS y sus discípulos HeIKo LeSCH y Michael PAWLiK. Lo que comparten estos modelos teóricos es considerar a la imputación como la totalidad del delito. Objeto de imputación es tanto el ilícito como la culpabilidad. Ahora bien, las diferentes teorías que se enrolan en esta corriente difieren en el grado en que se apartan de las categorías aportadas por la tradicional teoría del delito, así como en el contenido y en el grado de independencia entre los diversos juicios de imputación. No constituye la finalidad del presente artículo describir la totalidad de los modelos, sino solo presentar de manera sintética tres modelos seleccionados.

\section{La teoría de la Imputación de WERnER HARDWIG}

A través de su concepto de imputación, HARDwIG quiere mostrar las relaciones de compleja naturaleza que se establecen entre los elementos, para él fundamentales, del sistema normativo: el sujeto de derecho (Rechtssubjekt), el Derecho (Recht) y el suceso jurídico (Rechtsgeschehen). Para este autor, los conceptos de causalidad e imputación están relacionados a dos formas de reflexión completamente diversas. Por ello, de ningún modo es posible considerar el sentido de la imputación de un modolineal-progresivo-retrospectivo, como sucede con la causalidad. A través del concepto de imputación, es razonable asociar a otra manera de reflexión, que este autor imagina gráficamente como un círculo con tres puntos en los que están unidos, en relación recíproca, el Derecho, el sujeto de derecho y el suceso jurídico. Estos tres puntos constituyen un complejo sistema de referencia de carácter cerrado. En él, ningún punto puede ser abstraído de los otros, porque con ello su relación de sentido se interrumpiría. Al mismo tiempo, niega que dicho sistema se pueda presentar de manera progresiva desde un punto a otro, porque en esa progresión se establece un punto como inicio, lo que no resulta posible conforme a su modo de compresión. En esta complejidad, el concepto de imputación significa la producción formal de esas 
relaciones. Entonces, con el concepto de imputación está asociado, además de un especial modo de reflexión, un sistema especial (HARDWIG, 1957: 175).

HARDWIG considera a la teoría general de la imputación como una compleja relación de carácter cerrado que debía comprender la totalidad del sistema jurídico-penal, constituyéndose en el núcleo del mismo. Su teoría de la imputación, proyectada en la teoría del delito, alcanza hasta la categoría de la culpabilidad y la misma es idónea para toda manifestación delictiva, sean los delitos resultado o de mera actividad, dolosos o imprudentes, de comisión o de omisión.

Este autor desarrolla un modelo de análisis en el que deja de lado el modo de entender el delito hasta ese momento imperante, o sea, rechaza el dogma causal como fundamento para la atribución de resultado. Por el contrario, de acuerdo con su punto de vista, el fundamento de la atribución está ligado a una conducta infractora de un deber $^{11}$. Como afirma HARDWIG,

La norma de valoración, por tanto, no reza: tú no debes causar la muerte de una persona, sino: debes evitar causar la muerte de una persona (por supuesto, siempre que sea para ti evitable) $)^{12}$.

Desvalorada por el Derecho penal es siempre la conducta y no el resultado ${ }^{13}$. El efecto jurídico considerado como antijurídico, es tan solo un suceso fáctico que es relativo al Derecho y que, por tanto, es valorado de manera negativa. El Derecho prohíbe u ordena determinados modos de comportamiento humano; pero al hombre solo se le puede ordenar o prohibir aquello sobre lo cual tiene influencia. De esto se deduce que el Derecho solo puede ordenar o prohibir modos de conductas que dependan del

11 Desde la teoría de HARDwIG, el Derecho es a la vez norma de valoración (Bewertungsnorm) y norma de determinación (Bestimmungsnorm). La norma de valoración siempre precede de manera lógica a la norma de determinación. La relación lógica debe ser pensada de esta manera: así, la norma de determinación que reza "no debes matar", está basada en una norma de valoración, precisamente la referida a la inviolabilidad de la vida. El derecho no es mera valoración, tales valoraciones pueden ser pensadas independientemente de él. Antes bien, la finalidad primordial del Derecho es determinar conductas humanas. En este esquema, la norma de valoración y la norma de determinación se presuponen recíprocamente: una norma es norma de valoración cuando presupone una conducta determinable (HARDWIG, : 1957: 165-166).

12 "Die Bewertungsnorm lautet deswegen auch nicht: Du sollst nicht den Tod eines Menschen verursachen, sondern: Du sollst es vermeiden, den Tod eines Menschen zu verursachen (verseht sich: sofern es für dich vermeidbar ist)" (HARDWIG, 1957: 166).

13 Según HARDwig, esa acción u omisión pueden tener consecuencias, que llamamos resultado (Erfolg). El resultado que es relativo, en términos casuales o de manera final, a una conducta contraria a un deber jurídico podemos llamarlo "resultado antijurídico", aunque HARDWIG aclara que esta forma de expresión no es ciertamente correcta. Según él (1968: 289), se debería decir: "un resultado, que se basa en una conducta contraria al deber". 
poder y voluntad del hombre ${ }^{14}$. La norma presupone que puede ser cumplida (Erfüllbarkeit des Rechts), lo que en otros términos significa que ella reclama la libertad del hombre (HARDwIG, Op. cit.: 20).

HARDWIG reconoce dos niveles diferenciados de imputación que se llevan a cabo a través de diversos juicios; ellos son: la imputación de la antijuridicidad y la imputación de la culpabilidad. El ilícito (Unrecht) existe cuando se ha lesionado una norma de determinación, cuya lesión era en principio posible evitar. Contrario sensu, aquello que no puede ser evitado no puede ser antijurídico. Antijurídico es el suceso en referencia al cual un sujeto se ha comportado antijurídicamente, es decir, ha lesionado un deber jurídico. Por el contrario, culpable es la conducta que contradice la misma norma de valoración y de determinación en referencia al autor concreto, según su discernimiento y capacidad volitiva (es decir, su capacidad concreta-individual o "subjetiva"). En la culpabilidad se constata que el sujeto de derecho, según sus concretas capacidades, hubiese querido evitar o elidir lo que había querido.

\section{El modelo teórico propuesto por JOACHIM HRUSCHKA}

HRUSCHKA es un seguidor de la doctrina de la imputación propuesta por KANT. Enrolado en posturas neokantianas, concibe al Derecho en cuanto objeto (Gegenstand) de análisis bajo el modo de contemplación moral (moralische Betrachtungsweise), y rechaza toda explicación naturalística del fenómeno normativo.

Este autor considera que la actual dogmática jurídico-penal no constituye una teoría coordinada, articulada y comprensiva (HruschKA, 1985: 2) ${ }^{15}$. No obstante, el Derecho penal debe aspirar a tal finalidad. A tal fin, debe construir sistemas de casos y establecer las condiciones de racionalidad de las propuestas de solución de los problemas que siguen vigentes. Se debe axiomatizar la teoría general del delito y expresarla en una doctrina cerrada, libre de contradicciones, y que incluya todos los aspectos parciales, manteniendo los axiomas entre sí lo más independiente posible ${ }^{16}$.

14 Para Hardwig (1974: 20), en cuanto norma de determinación, el Derecho se dirige a la generalidad, constituyendo esta su función primaria. El Derecho, como también las normas morales, son vinculantes, entonces son imperativos, de los cuales no está permitida una desviación. Pertenece al concepto de norma que ella sea pensada como obligatoria. Esa obligatoriedad es incondicional tanto en las normas de la ética como en las normas del Derecho. Mientras en general valen, valen con absoluta obligatoriedad.

15 HRUSCHKA sostiene que cuando una regulación es cuestionable, lo correcto es criticarla y proponer su sustitución, en lugar de aparentar que sigue siendo la regulación deseable y que el resultado pretendido puede obtenerse a través de una interpretación más o menos correcta (HRUSCHKA, 1988: XIX).

16 HruschKa (JZ, Op. cit. (n. 21): 8). Según HruschKa (1981: 237), las funciones que debe cumplir la dogmática son tres: 1) analizar las estructuras subyacentes a los sistemas jurídico-penales de normas; 2) efectuar consideraciones ético-normativas (político-jurídicas) a los fines de determinar si una conducta es merecedora de pena o no; 3 ) elaborar y comentar el Derecho positivo. La finalidad 
En el modelo de Derecho penal propuesto por este filósofo del Derecho y penalista, el concepto imputación (Zurechnung) se erige como la categoría fundamental de la teoría por él propuesta. De este modo, considera que conceptos tales como acción, libertad y culpabilidad no pueden ser suficientemente comprendidos sin referencia al concepto de imputación en sí, ni en su relación recíproca (HRUSCHKA, 1976: 3).

HRUSCHKA sostiene que desde el punto de vista epistemológico un determinado fenómeno, sea un movimiento corporal o un sonido, puede ser contemplado en función de dos diversas modalidades de pensamiento. Dichas modalidades de contemplación son la natural (naturalische Betrachtungsweise) y la moral (moralische Betrachtungsweise). Ellas constituyen posibilidades del pensamiento y la adopción de una u otra posibilidad no está establecida en función del criterio de verdad (Wahrheit), sino en función de la exactitud (Richtigkeit). En el modo de contemplación moral, el sujeto reflexiona sobre sí y sobre la comunidad de sujetos en la que se encuentra, y es en esta comunidad en la que los sujetos contemplan el mundo de manera natural (HruschKA, Op. cit.: 9). A partir de este modo de contemplación, desarrolla su teoría del Derecho.

HRUSCHKA retoma el modelo de imputación kantiano al que le suma un profundo análisis desde la teoría de las normas. Toda conducta humana, toda acción, sea un movimiento corporal o un sonido, puede ser definida como el seguimiento de una regla. En todas nuestras conductas aplicamos reglas: toda nuestra conducta, incluido nuestro idioma, solo se puede comprender como la observancia cierta por la conducta de reglas predefinidas ${ }^{17}$. Al respecto sostiene:

Definimos un suceso -un movimiento corporal, un sonido- como acción, siempre y cuando aceptamos que ese sujeto en ese suceso aplica una regla ${ }^{18}$.

3 depende de la 1 y 2 . Así como la 2 depende de la 1 . La función 1 , en cambio, es independiente de las demás funciones.

17 También en las actividades sin propósito seguimos reglas; en los silbidos desafortunados, entre otras cosas, importa la regla de la melodía de la canción (HRUSCHKA, sZ, cit. (n. 23): 12).

18 "Wir begreifen einen Vorgang - eine Körperbewegung, einen Laut - als Handlung, wenn und weil wir annehmen, dass ein Subjekt in diesem Vorgang eine Regel anwendet" (HRUSCHKA, SZ, cit. (n. 23): 12-13). Pese a que HruschKa no cite a PETER WINCH, existe un profundo paralelismo entre esta definición planteada y la propuesta por el filósofo del lenguaje. WINCH sostiene que el comportamiento regido por reglas es esencialmente social. El mismo supone convenciones y acuerdos intersubjetivos. Los sujetos, cuando actúan, lo hacen mediante la aceptación y la observancia de reglas, aunque las mismas permanezcan implícitas. Al respecto aclara: "El concepto de seguir una regla (...) sugiere que se han de tener en cuenta no sólo las acciones de la persona cuya conducta como candidato para la categoría de seguidor de reglas está en cuestión, sino también las reacciones de otros individuos ante lo que él hace. Dicho de manera más específica, sólo en una situación en la que tiene sentido suponer que alguien más puede, en principio, descubrir la regla que estoy siguiendo, es posible decir inteligiblemente que estoy, de algún modo, siguiendo una regla" (WINCH, 2003: 30). 
Define la imputación de una acción como el seguimiento de una regla. En la imputación de un suceso como acción se requiere que el sujeto aplique un específico grupo de reglas, conjunto de reglas que es conocido tanto por el sujeto imputante como por el sujeto imputado.

La imputación es un juicio que los sujetos emiten, atribuyen. Imputación significa que no contemplamos la acción imputada como un eslabón de una cadena causal sino como un nuevo comienzo. A partir de la imputación de sucesos físicos podemos comprender (verstehen) o comprender mal (missverstehen) la acción de un sujeto. Siempre que se contemple una acción o la omisión de una acción (específica), dicha acción que percibimos es el producto de una imputación hecha por nosotros. Mediante la imputación de acciones, los individuos se reconocen como libres. No hay en ello ficción alguna. La aceptación de tal libertad es una condición de posibilidad de la racionalidad que aceptamos para nosotros mismos (HRUSCHKA, 1998: 585). La imputación requiere libertad ${ }^{19}$; en este punto retoma el concepto kantiano de libertad, en el sentido de libertad transcendente como lo es la expresión causa libera. La imputación se hace posible en la medida en que se interrumpe el proceso causal y se escoge, entre la multiplicidad de causas, aquella que da origen al suceso, su causa libera.

HRUSCHKA construye su modelo de comprensión a partir de un sistema lógico de normas, distinguiendo entre reglas de conductas (Verhaltensregeln) y reglas de imputación (Zurechnungsregel). Las reglas de conducta están compuestas por un sistema de prohibiciones, prescripciones, eximentes y permisiones ${ }^{20}$. En su dimensión prospectiva, dicen qué acciones del respectivo sistema de reglas hay que entender como prescriptas, prohibidas, (relativamente) permitidas y (relativamente) eximidas. Las normas de conducta en la dimensión retrospectiva las denomina applicatio legis ad factum, sirviéndole al juez como baremo para determinar si la acción es conforme o no a la norma. En este estadio se produce una circularidad hermenéutica entre el hecho y la norma, puesto que, para considerar el suceso como un hecho, es decir como acción u omisión del autor, se deberá tener en cuenta el respectivo tipo penal, con el que luego se determinará si el autor ha cumplido o no con el deber impuesto por el mismo (applicatio legis ad factum). Se desarrolla así un ir y venir entre el hecho y la norma, ocasionando una estructura circular de entendimiento.

19 En términos de HruschKa, "la libertad es la independencia de un proceso -de una acción- respecto de la suma de condiciones iniciales precedentes, esto es, la independencia del que actúa respecto de los impulsos que lo determinan" (HruschKA, ZStW 110, cit. (n. 27): 383).

20 Conforme al hexágono deontológico, este autor considera a las eximentes como la oposición de contravalencia (excepciones) de las prescripciones, así como las permisiones lo son respecto de las prohibiciones (HRUSCHKA, 2004: 780-784). 
Existe otro sistema de reglas compuesto por normas de imputación. Ellas forman parte de un sistema de reglas propio ${ }^{21}$. Solo operan en una dimensión retrospectiva y el destinatario de la misma es el juez (sujeto imputante). Como consecuencia de los juicios de imputación, podemos denominar a los sucesos como hechos y atribuírselos a su destinatario como reprochables.

HRUSCHKA desarrolla dos niveles de imputación mediados por la actividad de interpretación de la norma ${ }^{22}$. El primer nivel de imputación (imputatio facti) es un juicio de adscripción por el cual un suceso es considerado como hecho (Tat) y el sujeto actuante u omitente, como su artífice (Urheber). El imputar el hecho es condición necesaria para su valoración. Juzgar si el hecho imputado (en el primer nivel) es antijurídico, no es ningún juicio de imputación, sino expresión de que el mismo no concuerda con el sistema vigente de reglas de comportamiento del que se parte, propio de la applicatio legis ad factum. La imputatio iuris es un juicio por el cual se considera que el artífice (Urheber) con conocimiento de la antijuridicidad de su hecho, por una parte, tuvo un motivo para omitir la acción prohibida o bien para realizar la acción ordenada y, por otra parte, no tuvo ningún contramotivo comprensible que le impidiera el cumplimiento de su deber (HRUSCHKA, 1991: 455).

HRUSCHKA enuncia tres principios en los que opera la exclusión de la imputatio facti, a saber: a) "respecto de lo imposible no puede haber imputación alguna" (Impossibilium nulla est imputatio), se presenta cuando el supuesto autor se encuentra en una situación en la que la ejecución de la acción le era físicamente imposible; b) "respecto de lo necesario no puede haber imputación alguna" (necessarirum nulla est imputatio), es una extensión del primero para los casos de necesidad física. En estos casos, el autor se encuentra bajo la influencia de una necesidad física (vis absoluta); c) "respecto de lo que el sujeto no ha conocido no puede haber imputación alguna" (ignoratum nulla est imputatio); el virtual autor no ha tenido conocimiento de la si-

21 En sentido contrario se manifiesta REINHOLD (2009: 117), quien sostiene que la regla de imputación es el sentido formal y material de la norma, cuya aplicación ella posibilita; ella es su sentido y su sensor y, por lo tanto, nada que se pueda comprender como algo independiente opuesto a la norma. Dicho en otros términos, las concretas (reales) reglas de imputación no son separables de las normas jurídico-penales cuya aplicación ellas posibilitan (reglas de conducta).

22 GÜNTHER, al analizar de manera crítica el sistema de HRUSCHKA, sostiene que en el primer nivel de la imputación la libertad debe ya ser presupuesta en el sentido de poder actuar de otro modo, cuando una consecuencia de la conducta debe ser caracterizable como un actuar, a diferencia de un suceso físico. Solo después de que ha sido imputada una acción a un acto, puede ser medida su conformidad a Derecho o su antijuridicidad en la regla de una norma de comportamiento que prohíbe, prescribe o permite esa acción. En el segundo nivel de la imputación, la antijuridicidad de la acción del actor es imputada a la culpabilidad. Simultáneamente, el actor debe ser nuevamente presupuesto como persona libre. Solo entonces es fundado el juicio, que el actor ha tenido a pesar de su motivación de realizar lo prohibido con la consciencia de la antijuridicidad, también un motivo para omitir la acción prohibida. Así entendidas, las reglas de imputación del primer y segundo nivel implican un concepto formal de libertad que, cada una de ellas, también parece ser compatible con una norma de conducta ilegítima (GÜNTHER, 1994: 144-145). 
tuación relevante. Aquí estamos ante el supuesto de falta de dolo (ignorantia facti) (HRUSCHKA, 1991: 454-455). Para el caso de la imputatio iuris, HRUSCHKA establece un paralelismo con la imputatio facti con los mismos principios de exclusión de la imputación. Ellos son: a) ignoratorum nulla est imputatio, en tanto al aplicar este principio no se imputan las ausencias de conocimiento de la antijuridicidad, es decir, el error de prohibición o de prescripción, como también ciertas enfermedades o trastornos mentales que imposibilitan acceder al conocimiento de la norma (ignorantia iuris); b) imposssibilium necessariorum nuella est imputatio, que permite eximir de reproche, entre otras circunstancias, cuando el autor actúa antijurídicamente en una situación de necesidad (vis moralis) (HruschKA, Op. cit: 456). Se trata de la realización de hechos en la cual el autor se encuentra en una situación de necesidad que ni excluye la acción ni su antijuridicidad y, a pesar de ello, el Derecho le concede relevancia.

Para poder atribuir responsabilidad a estos casos, desarrolla un sistema paralelo denominado imputación extraordinaria (außerordentliche Zurechnung). Esta tiene lugar cuando el sucedáneo (Surrogat) es tratado como sustitución suficiente por el faltante elemento constitutivo del delito (NEUMANN, 1987: 582-583). El suceso será atribuido al agente y reprochado al mismo, no en razón de la infracción de un deber (Pflicht), sino porque el sujeto obra en contra de lo que le incumbía ${ }^{23}$. Las incumbencias (Obliegenheiten) se presentan como fuentes de pautas de comportamientos que no llegan a ser reglas de actuar, pero las posibilitan. Las incumbencias no fundamentan el reproche de culpabilidad, sino que solo bloquean una disculpa del autor. Para distinguir entre aquellas consecuencias imputables de aquellas cuya imputación queda excluida, HRUSCHKA recurre a la distinción hecha por SAMUEL PUFENDORF entre actio libera in se (acción libre en sí misma) que fundamenta la imputación ordinaria y actio libera in causa (acción libre en su causa) principio de la imputación extraordinaria. Por su parte, una acción que no fue libre, ni considerada en sí misma ni en su causa, no puede ser imputada (actiones neque in se neque in sua causa liberae) (HRUSCHKA, 1984: 662-664). Así, en el primer juicio de imputación, pese a darse un supuesto vis absoluta, se podrá imputar al sujeto si el agente es responsable de su falta de capacidad. Lo mismo ocurre con los supuestos de ignorantia facti; en este caso, se imputa de manera extraordinaria porque el agente es responsable de su falta de conocimiento. Los casos de ignorantia facti imputables de manera extraordinaria al agente no son otra cosa que el universo de los delitos imprudentes. A su vez, ese paralelismo se puede trazar en la imputación de segundo nivel. Respecto de los casos de ignorantia iuris, se van a imputar de manera extraordinaria cuando al sujeto le incumba el conocimiento de la norma o bien debía adecuar su conducta a dicha comprensión. Estas son las situaciones tratadas por la teoría del delito como de error

23 Las incumbencias resultan de imperativos hipotéticos, no de imperativos categóricos (NEUMANN, 1985: 584). El actio praecendens en tanto lesión de la incumbencia no es objeto, sino fundamento de la imputación jurídico-penal; ella solo justifica el hacer responsable de manera excepcional al autor por su conducta típica, aunque él lo haya perpetrado en una situación de incapacidad de acción (ídem: 392). 
de prohibición vencible y los casos de vis compulsiva, que son imputados de manera extraordinaria cuando el sujeto sea responsable de su situación de necesidad.

\section{La teoría de la imputación según JAKOBS}

El modelo propuesto por GÜNTHER JAKOBS también queda comprendido dentro del concepto amplio de imputación. JAKOBS no rechaza que la teoría del delito por él desarrollada constituya una teoría de la imputación, sino que, por el contrario, la presenta como tal. Ya en el prólogo de su Lehrbuch, adelanta que su teoría de la imputación se centra en quién es sujeto competente del suceso ${ }^{24}$. Entiende que la pena y la imputación se refieren la una a la otra, en una relación sinalagmática. La pena es una respuesta a la conducta delictiva del autor que, en consecuencia, es comprendida como comunicación. Con esta interpretación como discurso y respuesta, el hecho punible y la pena dependen de la respectiva configuración de la sociedad, como comunicaciones sobre la estructura normativa de la misma (JAKOBS, 2012: 13-14).

Respecto de la función que cumplen las normas jurídico-penales, JAKOBS se aparta de la doctrina mayoritaria que las concibe como norma de determinación (Bestimmungsnorm). Niega que las normas jurídico-penales tengan una función de influir sobre el comportamiento de los ciudadanos. Conforme a su punto de vista, el Derecho se presenta en su visión sistémica como comunicación, como una estructura de la sociedad -como un subsistema social-, y tanto los deberes como los derechos, en términos sistémicos "las expectativas normativas", no están dirigidos a individuos, sino a destinos construidos de manera comunicacional, que se denominan "personas" (JAKOBS, 2004: 3) ${ }^{25}$. Así, desde el punto de vista de la sociedad, no son las personas las que fundamentan la comunicación personal, sino que es la comunicación personal la que pasa a definir a los individuos como personas o, en otros términos, la persona surge en el contexto de la comunicación ${ }^{26}$. JAKOBS pretende abordar el delito no como un fenómeno circunscripto a la relación entre norma e infractor, sino como un fenómeno social en el que la víctima y la colectividad se ven afectadas. La función de determinación solo la contempla como una función latente, como un efecto

24 "Si se parte de la misión del Derecho penal y no de la esencia (o de las estructuras) de los objetos de la Dogmática penal, ello conduce a una (re)normativización de los conceptos (...) los conceptos de causalidad, poder, capacidad, culpabilidad, etc., pierden su contenido pre-jurídico y se convierten en conceptos que designan grados de responsabilidad o incumbencia...” (JAKOBS, 1991: VII).

25 En sentido similar, JАKOBS (2003: 43). En términos de JAKOBS: "Ser persona significa tener que representar un papel. Persona es la máscara, es decir, precisamente no es la expresión de la subjetividad de su portador, "sino que es representación de una competencia socialmente comprensible" (JAKOBS, 1995: 859). 
secundario, bien recibido pero ajeno, en principio, a la lógica del Derecho penal (Silva SÁnCheZ, 2003: 21-22). Al respecto, JAKOBS sostiene:

La sociedad surge cuando la norma proporciona la pauta rectora de la comunicación, esto es, determina a qué comportamientos y cómo hay que adherirse ${ }^{27}$.

La imputación jurídico-penal, conforme a su tesis, tiene la función de determinar el caso en el que la norma, por causa de la conducta (delictiva) de una persona, debe ser corroborada cognitivamente. Con otras palabras, la imputación jurídico-penal establece cuándo un acontecimiento (Ereignis) es comprendido como contradicción de la norma (Normwiderspruch), como manifestación de una persona competente. El sistema alcanza sin dudas algo más; luego, también la imputación jurídico-penal y la pena construyen una función de unidad (Funktionseinheit), asimismo un sistema. Cuando JAKOBS habla de sistema, no se trata del sistema penal como parte del sistema jurídico y este, nuevamente, como parte del sistema social, sino que el concepto de sistema lo entiende como lo hacen de manera usual las ciencias del espíritu (Geisteswissenschaften): como una consistente relación de juicios ${ }^{28}$.

El mundo moderno debe ser ordenado conforme al sentido de las personas y eso implica que el hecho delictivo debe ser entendido como suceso significativo, como contradicción de la norma, como producto intelectual. Las reglas para tal comprensión producen, en su conjunto, la teoría de la imputación. Lo que no puede ser imputado es el destino como donante de significado en la modernidad, y debe ser descartado como sin sentido, es decir, naturaleza. El código mediante el cual el desarrollo del sistema de imputación se concretiza reza "sentido" versus "naturaleza", que en el ámbito jurídico-penal se expresa como "sentido delictivo versus naturaleza" (deliktischer Sinn versus Natur $)^{29}$. Cuándo un hecho es interpretado como naturaleza y cuándo con sentido delictivo, se determina en función de las necesidades de estabilización social. El sentido delictivo está íntimamente ligado al concepto de culpabilidad sostenido por este autor.

Mientras JАKOBS, en el tratamiento de "Culpabilidad y prevención” (Schuld und Prävention) del año $1976^{[30]}$, la interpretación preventiva y justificación jurídica del concepto de culpabilidad relacionaba explícitamente al sistema jurídico del momento y por ello la legitimidad ya estaba implícita en la orden (GÜNTHER, 2005: 51), cuya estabilización debía ser la finalidad de la pena y de la imputación; JAKOBS diferencia

27 "Gesellschaft entsteht, wenn die Norm den die Kommunikation leitenden Maßstab abgibt, also bestimmt, an welches Verhalten wie anzuschließen ist" (JAKOBS, 1999: 52). Luego añade: "las normas no dirigen el comportamiento, sino que lo explican como perteneciente a un ordenamiento o no" (ídem: 54).

28 JAKOBS, GÜNTHER: $S s Z$, cit. (n. 39), p. 16.

29 JAKOBS, GÜNTHER:SsZ, cit. (n. 39), pp. 22-23.

30 Véase Jаковs (1976). 
explícitamente en el tratamiento de "El principio de culpabilidad" (Das Schuldprinzip) del año 1993 un concepto formal de culpabilidad válido para cualquier orden, de un concepto material que se encuentra solo en órdenes legítimas. A partir de este momento, el concepto de culpabilidad tiene un sentido material que va más allá del contenido meramente formal consistente en la afirmación de la culpabilidad como medio para garantizar la estabilidad social. El contenido material de la culpabilidad se manifiesta en la medida en que el delito es interpretado como una perturbación proveniente de una persona, y no de un animal o una cosa. La imputación vincula el suceso entendido como un esbozo de la realidad, y la pena, como contradicción del esbozo de sociedad representado por el autor, considerando a este en tanto persona. En este sentido, JAKOBS recurre a HEGEL ${ }^{31}$ al afirmar que solo considerando al delincuente como persona pueden comprenderse el hecho y la pena como contexto de sentido y no como secuencia irracional de dos males (JAKOBS, 2003: 43-44).

Siguiendo a KLAUS GÜNTHER, podemos decir que en JAKOBS la imputación a la persona significa que esta es aislada de una multitud de posibles causas y circunstancias que pueden explicar la defraudación de la expectativa. En este esquema, la persona es explicada por la única causa. Esta debe estar en condiciones de procurar que nadie pueda ser responsable por sus efectos a excepción de la persona misma. En caso contrario, serían responsables otros sujetos por la frustración, quizás incluso el propio expectante, que debería revisar sus expectativas. Por lo tanto, la persona debe ser constituida de manera que la imputación esté relacionada con algo, con una motivación, que solo puede ser asignada a la persona. Ella vale como fuente de error y por su motivación cada uno es responsable. La defraudación de la expectativa puede, entonces, ser explicada de manera que su causa se basa en la motivación errónea, o sea, en la motivación no conforme a Derecho, en un defecto en el respeto de la norma, por el cual la persona es responsable (GÜNTHER, 2005: 43). Por otro lado, las causas del defecto de dicha motivación solo incumben al autor y así como también las patologías u otras alteraciones que padezca el autor que indican que se trata de un sujeto al que no se le puede realizar el juicio de imputación como culpable, por-

31 "La vulneración con la cual es afectada la voluntad que es en sí (es decir, respecto a la voluntad de aquel que viola, así como a la del vulnerado y de los demás), no tiene existencia positiva en esa voluntad, que como tal es en sí, como tampoco en el simple producto. Por sí, esta voluntad que es en sí (Derecho, Ley en sí), es, más bien, lo exteriormente no existente y, a este respecto, inviolable. La vulneración, para la voluntad particular del ofendido y de los demás, es sólo algo negativo. $L a$ existencia positiva de la vulneración es sólo en cuanto voluntad individual del delincuente. La vulneración de esta voluntad en cuanto existente es la anulación del delito, que de otro modo sería válido; es el restablecimiento del Derecho" (HEGEL, 2009: § 99,p. 195); por su parte en el $\$ 100$ afirma que no se trata solo del concepto de delito, de lo racional del mismo en y por sí, que el Estado debe hacer valer con o sin el consentimiento de los individuos, sino que, además, en la acción misma del delincuente está la racionalidad formal, el querer del individuo. Al considerar que la pena contiene su propio derecho, se honra al delincuente como un ser racional. No se le concederá este honor si el concepto y la medida de la pena no se toman del hecho mismo, si se lo considera como un animal dañoso que hay que hacer inofensivo, o si se toma como finalidad de la pena la intimidación o la corrección (ídem: 199-200). 
que no se la puede considerar como miembro pleno del ámbito social que regula el Derecho (LóPEz DíAz, 2006: 211): o sea, solo formalmente es persona. Sus hechos son interpretados como mera naturaleza.

Resumiendo, JAKOBS se aboca a la finalidad de desarrollar una teoría de la imputación que abarque toda la teoría del delito, no entendiendo al delito en términos descriptivos, sino como un problema de imputación. La imputación no se limita a establecer criterios correctivos de la causalidad, sino que pretende determinar quién es el sujeto competente por el hecho ilícito. Imputación, para este autor, es imputación culpable, lo demás es naturaleza. Este autor deriva la imputación de la propia función de la pena, dado que la imputación establece a qué persona ha de penarse para la estabilización de la norma o, en otros términos, quién es el sujeto competente por el hecho ilícito. Así,

Ha de castigarse al sujeto que se ha comportado de contrariedad a la norma y culpablemente (si es que la ley no renuncia a la pena, lo que es posible por diversos motivos). La teoría de la imputación desarrolla los conceptos que se han empleado: comportamiento del sujeto, infracción de la norma y culpabilidad $^{32}$.

\section{IMPLICANCIAS DE LA DOCTRINA DE LA IMPUTACIÓN EN LA TEORÍA DEL DELITO}

Las condiciones para la atribución de responsabilidad son objeto tanto de la teoría del delito como de la doctrina de la imputación. Lo particular de la teoría del delito es la concreta división en niveles, estratos o categorías sistemáticas con arreglo a los cuales se efectúa la atribución de responsabilidad. A continuación, cotejaremos los modelos analizados con las respectivas categorías de la teoría del delito, a fin de determinar qué impacto producen estos modelos teóricos en aquella teoría.

\section{Las categorías del sistema de HARDWIG: injusto y culpabilidad}

La teoría de la imputación desarrollada por HARDWIG, contrastada con la teoría del delito, conlleva a la admisión de una estructura bimembre del delito, compuesta por el ilícito y la culpabilidad. Con respecto a la relación entre tipo y antijuridicidad, no existe una relación indiciaria, sino solo un tipo de ilícito (Unrechtstatbestand) en el

32 "Zu bestrafen ist ein Subjekt, das sich normwidrig und schuldhat verhalten hat (wenn nicht das Gesetz auf Strafe verzichtet, was aus diversen Gründen möglich ist). Die Lehre von der Zurechnung entwickelt die verwendeten Begriffe: Verhalten des Subjekt, Normbruch, Schuld" (JAKOBS, AT, cit. (n. 38): 126). 
cual la antijuridicidad es una característica necesaria del tipo (HARDWIG, 1957: 181). $\mathrm{Si}$, conforme el modelo propuesto por este autor, el tipo es la descripción de un ilícito, no tiene sentido distinguir entre un tipo, por un lado, y un ilícito, por otro. Ergo, no se puede comprobar si se presenta un tipo y comprobar luego si ese tipo es ilícito o no. Tanto la comprobación de la conducta típica como su antijuridicidad pertenecen conjuntamente a la comprobación del tipo (ídem: 182-183).

En esta estructura, dolo e imprudencia son conceptos complejos que contienen algunos momentos que pertenecen al tipo penal, mientras todos los momentos juntos forman parte de la culpabilidad. En el modelo propuesto por HARDWIG, dolo e imprudencia se diferencian al principio en el momento de la intencionalidad. Alguien actúa de manera dolosa en la medida en que quiere hacer u omitir algo, sabiendo que eso que él quiere hacer u omitir es ilícito, dado que él podría haber determinado su voluntad conforme al Derecho. En este esquema, la capacidad de culpabilidad no es componente del tipo, sino su sustancia. Componente tipo, por lo tanto, solo puede ser el conocimiento y la voluntad del hecho más la conciencia de la antijuridicidad (das Wissen und Wollen der Tat und das Unrechtsbewusstsein) (ídem: 185-186). En este punto, HARDWIG se diferencia WELZEL, quien por medio de su teoría finalista había logrado escindir el conocimiento del hecho y voluntad del mismo correspondiente al dolo, ubicado sistemáticamente en el tipo penal, de la consciencia de la antijuridicidad que la ubica sistemáticamente en el nivel de la culpabilidad. Para HARDWIG, por el contrario, el dolo perteneciente al tipo es un dolo desvalorado. El mismo es en parte componente del tipo y en parte de la culpabilidad. Fundamenta esa doble ubicación del dolo en la afirmación de que la conducta tiene un significado fáctico, uno social y uno jurídico, no pudiendo ser separados dichos momentos sino que deben ser valorados en su conjunto. La complejidad de todas las relaciones es el fundamento de la teoría general de la imputación. En la voluntad del hecho está, por tanto, el ámbito del Derecho, el tener en cuenta el enfoque de la voluntad en referencia al Derecho. Este enfoque pertenece a la relación de culpabilidad, pero en tanto conciencia del hecho pertenece también al tipo (HARDWIG, Op. cit.: 181). Dicho de otro modo, para HARDWIG, el dolo es una clase de culpabilidad (Schuldart), puesto que dentro de la culpabilidad se examina si el autor ha hecho u omitido intencionalmente algo que es considerado ilícito, con conocimiento del mismo, aunque él podría haberse comportado conforme a Derecho. De esta relación de culpabilidad, pertenecen al tipo los componentes del conocimiento y voluntad del hecho y la consciencia de la antijuridicidad, mientras ambos, y su capacidad de determinar su voluntad conforme al Derecho, representan la relación de culpabilidad, que se deduce del juicio de culpabilidad. El juicio de culpabilidad se relaciona con el comportamiento fáctico, puesto que de ello se expresa que sea culpable (schuldhaft) (HARDwIG, Op. cit.: 196-197). Un modelo en el cual el primer estadio está conformado por la conducta antijurídica conlleva a que el objeto del dolo sea la conducta desvalorada, no pudiendo ser diferenciado analíticamente el error que recae sobre algún elemento configurador del hecho de aquel que recae sobre la valoración del mismo. 
En lo concerniente al delito imprudente, HARDWIG concibe la imprudencia como la violación de un deber de cuidado, dada la capacidad del autor de determinar su voluntad conforme a Derecho. En su esquema, al tipo penal del delito imprudente pertenecen los siguientes componentes: un deber jurídico de cuidado, una conducta que puede ser comparada con ese deber de cuidado y la violación del deber de cuidado. La estructura del delito imprudente refuerza su postura acerca de la existencia de un tipo total de injusto, dado que en el tipo del delito imprudente no resulta posible distinguir entre el tipo y la antijuridicidad. El concepto de imprudencia ya contiene como componente descriptivo la violación de un deber jurídico, justamente la violación del deber de cuidado. En la medida en que no se puede describir una conducta imprudente de otra manera que no sea como violación de un deber de cuidado, la división entre una descripción del hecho (tipo penal) y la antijuridicidad no es posible ${ }^{33}$. Resulta también dificultoso diferenciar en la imprudencia los momentos pertenecientes a la antijuridicidad y a la culpabilidad, respectivamente. El deber de cuidado reza que “emplea todas tus capacidades y fuerzas a fin de (umzu)...". En primer lugar, en ese "a fin de" se dividen los caminos de los dos modos de imprudencia. En el fondo no se puede distinguir para nada entre capacidades y fuerzas objetivas y subjetivas. En este punto, HARDWIG sigue la tradición y una necesidad cierta de diferenciar entre antijuridicidad y culpabilidad cuando efectúa la separación, incluyendo la capacidad concreta-individual de ese autor de determinar su voluntad conforme a Derecho, o sea, las capacidades de comprensión y voluntad concreta-individuales en la culpabilidad (HARDWIG, Op. cit.: 197-198).

\section{El modelo de HruSCHKA: imputatiofacti e imputatio iuris como categorías sistémicas}

Cotejando la doctrina de HruschKA con la teoría del delito, el esquema propuesto por este autor también desemboca en una teoría del delito de estructura bimembre. El primer estadio está compuesto por el hecho antijurídico (imputación de primer nivel más aplicación de la norma al hecho) y el segundo, por la atribución del hecho a la culpabilidad del autor (imputación de segundo nivel).

El primer nivel de imputación tiene por finalidad comprender un suceso como un "hecho" y atribuírselo a su artífice. Este primer estadio de imputación no se corresponde con el primer estrato de la teoría del delito, a saber, la acción. Como fue oportunamente explicado, la imputación es un juicio de adscripción, y en él no se constata algo en la realidad, una acción, sino que a partir de un juicio se afirma

33 "Fahrlässigkeit ist die Verletzung einer Sorgfalspflicht bei Gegebensein der Fahigkeit, seiner Willen dem Recht gemäß zu bestimmen" (HARDwIG, Op. cit.: 197). 
que un suceso es un hecho, se instaura una realidad ${ }^{34}$. Conforme a esta doctrina, no existe una realidad, una acción como dato primigenio y carente de valoración previa al hecho. Todas las energías invertidas por determinadas corrientes de la teoría del delito para distinguir la acción de la omisión se resuelven a partir de la valoración de la actividad o de la omisión en función de la regla de conducta que interviene en cada caso. Hay que resaltar que en este modo de proceder se visualiza una circularidad hermenéutica entre el hecho y la norma, puesto que para considerar el suceso como hecho hay que tener en cuenta la norma que luego será utilizada para valorar ese hecho como debido, meritorio o demeritorio.

El hecho está constituido por el componente cognoscitivo del dolo y el elemento volitivo consistente, en el control de lo conocido. El conocimiento de las circunstancias es condición necesaria para que el suceso, en el que se ve inmerso el agente, pueda ser considerado hecho y aquel, su Urheber. Solo se considerará hecho lo que es humano, susceptible de autocontrol y objeto de conocimiento (SÁNCHEZ-OsTIZ, 2008: 459). En este esquema, el dolo es un verdadero elemento configurador del hecho. El dolo es un verdadero juicio de imputación (adscripción): no se constata, sino que se afirma al considerar un suceso como hecho. Según HRUSCHKA (2001: 449), el agente obra de manera dolosa solo si se da el caso de que parte de la base de un hecho y de sus circunstancias que colman los presupuestos objetivos de un tipo delictivo, y además si no se da el caso de que parte de la base de las circunstancias que colman los presupuestos objetivos del tipo de una causa de justificación. En tanto, la doctrina de la imputación supone adelantar el análisis del dolo al primer juicio de imputación, y se rompe así con la lógica binaria propia de lo teoría del delito que considera a la imputación subjetiva un correlato del tipo objetivo.

Los casos de falta de conocimiento (ignorantia facti) solo podrán ser imputados de manera extraordinaria en la medida en que al sujeto le incumba dicho conocimiento. Esta doctrina demuestra la diversa naturaleza que media entre los delitos dolosos y los imprudentes, siendo estos últimos supuestos de imputación extraordinaria.

Dado que la adscripción del hecho al sujeto requiere no solo el conocimiento del suceso sino también la capacidad de control, ausente esta (vis abosoluta: casos de inconsciencia, movimientos reflejos, fuerza física irresistible) no se podrá proceder

34 En sentido similar, Jesús-María Silva SÁnchez (2003: 63-64) considera que acción es el acto de comunicación del sujeto. Qué sea acción-qué fenómenos son capaces de sentido- depende del sistema social en el que nos encontremos. En cuanto a la atribución de un sentido concreto a la acción, si bien la causalidad o la finalidad pueden constituir el fundamento de la misma, también hay que reconocer que la asignación de sentido puede provenir, en ausencia de una determinación precisa de ambas, de una adscripción de deberes en función de la posición ocupada por un sujeto en el seno del sistema o, en general, de reglas sociales de imputación. Asimismo, JAKOBS (1997: 102) sostiene que no es la naturaleza ni lo ontológico lo determinante en el ámbito del concepto de acción; de lo que se trata aquí es de interpretar la realidad social, de hacerla comprensible en la medida en que esté relacionada con el Derecho penal. 
a imputar de manera ordinaria, aunque, en determinadas circunstancias, se podrá realizar una imputación extraordinaria cuando el sujeto sea responsable de su incapacidad de actuar.

La applicatiolegis ad factumes al ámbito de valoración (interpretación de los tipos penales). Para HRUSCHKA,

...los tipos delictivos, junto con la cualificación de que un hecho que colma el tipo sería antijurídico, se hallan en el mismo plano lógico que las reglas de justificación, y no hay un plano de ‘justificación' que pueda diferenciarse del plano de los tipos delictivos. Si un hecho es o no antijurídico se enjuicia exclusivamente según el sistema de reglas sobre los delitos y las reglas de justificación como un todo y no según preceptos singulares entendidos aisladamente unos de otros (...) las normas facultativas (y permisivas) formulan excepciones a las prohibiciones y prescripciones, y las normas de justificación excepciones a los tipos delictivos ${ }^{35}$.

HRUSCHKA desarrolla un sistema de normas en el cual la norma prohibitiva o de mandato y la norma permisiva se encuentran en un mismo plano lógico, diverso al de las reglas de imputación. Esta construcción le permite a este autor diferenciar analíticamente entre el error de prohibición (ignorantia iuris) del error sobre los presupuestos objetivos de una causal de justificación (un caso de ignorantia facti). Este último, al recaer sobre un elemento objetivo de la norma permisiva, es idéntico al error de tipo, puesto que el dolo abarca ambos elementos. Esta postura llega a idénticas soluciones que la teoría de los elementos negativos del tipo, diferenciándose de ella en la medida en que no consideran las causas de justificación como elementos negativos del tipo penal sino como normas independientes que interactúan en un mismo plano lógico ${ }^{36}$.

Es en el ámbito de la valoración del hecho, de acuerdo con la norma, en el que se efectuaría la operación de la teoría del delito conocida como "imputación objetiva". Esta categoría no consistiría más que en la aplicación de criterios de interpretación de los tipos y no de una operación de imputación en sentido estricto (juicios de adscripción). El resultado, considerado como modificación del mundo exterior, carecería de sentido en Derecho penal si no estuviera vinculado a la idea de hecho como objeto

35 "Die Deliktstätbestände, verbunden mit der Bewertung, daß eine sie erfüllende Tat rechtswidrig sei, stehen auf derselben logischen Ebene wie die Rechtfertigungsregeln, und es gibt keine Ebene der "Rechtfertigung ", die von der Ebene der Deliktstatbestände zur unterscheiden wäre. Ob eine Tat rechtswidrig ist oder nicht, richtet sich ausschließlich nach dem System der Regeln über die Delikte und die Rechtfertigungsregeln als ganzem und nicht nach einzelnen als voneinander isoliert gedchten Vorschriften (...) die Erlaubnisnormen Ausnahmen zu den Geboten und Verboten, und die Rechtfertigungsnormen formulieren Ausnahmen zu den Deliktstatbeständen" (HRUSCHKA, 2001: 453-454).

HRUSCHKA (2001: 453-454; 2004: 780-784). 
primario de la imputación. El resultado no es en sí mismo fundamental, sino que el hecho es el objeto de la imputación ${ }^{37}$.

La última operación, constituida por la adscripción del reproche (imputatio iuris), es el momento de la valoración demeritoria del hecho. Dado que para imputar es necesario que el Urheber obre libremente (voluntariedad), la doctrina de la imputación ordinaria se cae cuando el autor no conoce la norma (ignorantia iuris) o bien cuando se encuentra imposibilitado de cumplirla (vis compulsiva). El primero de los supuestos de exclusión no solo incluiría los casos conocidos como error de prohibición, sino también aquellos de defecto de desconocimiento de la norma por enfermedades mentales (inimputabilidad). En los casos de imposibilidad de seguir la norma, se incluyen situaciones de estado de necesidad coactiva, como diversas enfermedades o trastornos mentales que influyen en la posibilidad de acatar la norma.

Un modelo de imputación que en determinados casos impone la violación de la incumbencia como núcleo de la imputación extraordinaria implica una determinada comprensión de la culpabilidad. Por consiguiente, la cuestión de la culpabilidad no se refiere a la fundamentación de un reproche de culpabilidad autónomo al reproche del ilícito, sino a la posibilidad del autor de defenderse contra el reproche de acciones responsablemente ilícitas ${ }^{38}$.

\section{La propuesta de JAKOBS: la acción como acción culpable. ¿Qué resta de la división entre categorías?}

De los modelos analizados, el sostenido por JAKOBS es que, al menos desde el plano formal, sigue respetando las categorías propias de la teoría del delito. Sin embargo, ya en los inicios de su teoría propone reformular la dogmática jurídico-penal hasta entonces vigente, arraigado en la tradición finalista. En contraposición, postula una desvinculación de la dogmática de las estructuras lógico-objetivas, depurando los conceptos básicos del Derecho penal de su referencia a la realidad (SCHÜNEMANN, 1995: 219); establece, en cambio, una normativización de la teoría del delito y de la metodología en general, poniendo en relación a la dogmática jurídico-penal con la finalidad del Derecho penal, que no es otra que la finalidad de la pena. JAKOBS sostiene que la mencionada renormativización del Derecho penal no debe abarcar solo a las categorías de la acción y la culpabilidad, sino que también el propio sujeto al que se imputa se presenta como un concepto funcional ${ }^{39}$. Al respecto, afirma que

37 El resultado cumple una función necesaria pero parcial a los efectos de la imputación, a saber, de prueba y acotación de la conducta (SÁNCHEZ-OsTIZ, 2008: 527-528).

38 NeUmann (ZStW 99, cit. (n. 35): 585).

39 JAKOBS (Op. cit. (n. 38), Vorwort, p. VII). 
El mundo de los conceptos jurídico-penales tiene que ajustarse a la tarea del Derecho penal y no a fenómenos naturales o de otro modo ajenos a lo social ${ }^{40}$.

En dicha empresa, al contrario de otras visiones funcionalistas, este autor no reconoce ninguna limitación de índole ontológica o incluso del sentido ordinario del lenguaje (SILVA SÁnchez, 2010: 111); el contenido del Derecho penal está dado en función de necesidades sistémicas, o sea, de la función de prevención general positiva $^{41}$.

La primera de las categorías sistémicas analizadas por JAKOBS en su teoría de la imputación es la acción. Ya en su Lehrbuch la identifica como un juicio de atribución cuando sostiene que

El concepto de 'acción' es, pues, una noción equívoca de la que ha de analizarse; se trata de lo que es un sujeto, de lo que es mundo exterior para el sujeto y de cuándo se puede vincular la conformación del mundo exterior con el sujeto (imputársela)" ${ }^{42}$.

JAKOBS trabaja con más profundidad esta categoría en su monografía El concepto jurídico-penal de acción. La define como una "expresión de sentido", lo que implica que el sujeto, a través de su conducta, defrauda las expectativas o, en otros términos, contradice la norma. Dicha contradicción es una expresión de sentido en la medida que su conducta implica una toma de postura frente a la validez de la norma, no reconociendo a la misma como máxima de comportamiento. La acción reside en la conducta de no reconocimiento de la validez de la norma. Basta que el resultado haya dado inicio a la producción del resultado. Este es solo una ulterior objetivación del hecho que incrementa cualitativamente el movimiento corporal ${ }^{43}$. JAKOBS identifica

40 JAKOBS (AT, Op. cit. (n. 38), Vorwort zur 2. Auflage, p. v).

41 Si bien el modelo teórico que ha propuesto JАKOBS tiene en sus orígenes un fuerte anclaje en el funcionalismo sistémico de NiKLAs LUHMANN, al tomar de este autor conceptos tales como sistema, norma, persona, etc., su teoría se ha visto modificada a lo largo de los años, acercándose a ideas hegelianas, especialmente en relación con el concepto de culpabilidad. Si bien no ha abandonado de manera total los aportes luhmannianos, no sería del todo errado hablar de dos JAKOBs: el primero, centrado en un modelo sociológico de Derecho penal y, el segundo, defensor de una teoría aún más radicalizada en su normativización, bajo la influencia de ideas hegelianas. Dicha absolutización ha llevado a que su teoría sea catalogada por ScHÜNEMANN (2001: 13-21) como "normativismo libre de empirismo" (empiriefreier Normativismus).

42 "Handlungsbegriff” ist also eine mißcerständliche Bezeichnung für das, was es abzuhandeln gilt; es geht darum, was überhaupt ein Subjekt und was für das Subjekt Außerwelt ist und wann die Gestalt der Außerwelt mit dem Subjekt verbunden (ihm zugerechnet) werden kann" (JAKOBS, AT, Op. cit. (n. 38): 137).

43 Según JAKOBS (1997: 118), acción es objetivación de la falta de reconocimiento de la vigencia de la norma, esto es, la expresión de sentido de que la norma en cuestión no es la máxima rectora. Expresión de sentido de un comportamiento que conduce o puede conducir a un resultado delictivo externo y 
a la acción con la imputación misma: en su esquema de interpretación toda acción jurídico-penalmente relevante es, al mismo tiempo, imputable. Así,

La acción y la imputación -y esta a su vez presupone la imputación del injusto- son lo mismo. El comportamiento, en cuanto suceso psíquico-físico, debe ser objetivamente imputable, evitable y culpable (JАKOBS, 1997: 124).

Conforme a esta definición, la culpabilidad es presupuesto de la imputación. Además, este autor considera que un concepto de acción acorde con la función del Derecho penal debe ser ampliado hasta la culpabilidad: acción es convertirse en culpable. Así, acción es aquel comportamiento que hace necesaria la imposición de una pena; en términos de JAKOBS, “acción es convertirse en competente por una lesión de la vigencia de la norma” (ídem).

Dentro de su concepto amplio de imputación, JAKOBS identifica un fragmento del mismo que lo denomina "imputación objetiva del resultado". Este concepto se refiere a la determinación de las propiedades objetivas y generales de un comportamiento imputable. Se trata de determinar qué significado tiene el comportamiento en el contexto social. Para ello no es suficiente el punto de vista del causador sino qué significado tiene el suceso acaecido en el mundo exterior, ya sea como hecho (jurídicamente relevante) o como infortunio. Conforme a JAKOBS (2004a: 85),

Esta interpretación en un contexto social del comportamiento unido a sus consecuencias causales o incluso a sus consecuencias causales atípicas, se lleva a efecto en la Dogmática moderna bajo en nombre de "imputación objetiva".

JAKOBS, en su Lehrbuch, no desconoce la necesidad lógica de distinguir entre dos juicios de imputación diferentes. Uno perteneciente al ámbito del injusto y otro a la culpabilidad. Ello se basa en la idea de que la falta de culpabilidad (por imposibilidad de conocer o cumplir la norma) presupone que la norma exista como tal con independencia de su cognoscibilidad o posibilidad de cumplirla. Por este motivo, aquello que es contrario a la norma, es decir el injusto, puede existir con independencia de la culpabilidad. JAKOBS, además, agrega que algunos preceptos pertenecientes al ámbito de la culpabilidad, específicamente aquellos que se refieren al injusto, no pueden formar parte de la norma, sino que constituyen un ámbito de "meta-reglas". De allí distingue entre el injusto como vulneración de la norma, por un lado, y por la culpabilidad entendida como la obligación de responder por la vulneración de la norma, por el otro. Sin embargo, esta distinción es puesta en duda en la medida en que su concepto de acción incluye al contenido de la culpabilidad y, más aún, que

evitable si este procedimiento, de acuerdo con un juicio comunicativamente relevante, es o podría ser la razón determinante del delito externo. 
en su reciente obra System der Strafrechtlichen Zurechnungpostula un tipo total de imputación (Gesamtzurechnungstatbestad) que abarcaría todos los presupuestos de la acción culpable ${ }^{44}$.

\section{LA IMPUTACIÓN: AVANCES Y RETROCESOS}

Luego de haber analizado cómo impactan estos modelos teóricos en la configuración de la teoría del delito, estamos en condiciones de establecer cuáles son los aportes, tanto positivos como negativos, que estas teorías proporcionan a la dogmática jurídico-penal. Dada la heterogeneidad que presentan los modelos analizados, que parten de presupuestos filosóficos y epistemológicos diversos, las conclusiones a las que arriban no pueden ser generalizables. Para poder juzgar si las teorías de la imputación significan nuevos bríos para la dogmática jurídico-penal actual o, por el contrario, una amenaza de destruir los logros científicos conquistados por esta, deben ser tenidas en cuenta dos cuestiones fundamentales: el análisis sistemático representado en la necesaria distinción entre injusto y culpabilidad, y el respeto a un mínimo sustrato ontológico.

El mayor aporte de la teoría del delito ha sido el análisis sistemático a través de diversas categorías. El estudio analítico del fenómeno delictivo ha configurado un hito en la historia del pensamiento penal que no puede ser dejado de lado, puesto que si se renuncia a la ordenación lógica, en términos de SchünEMANN (2012: 2), “[equivaldría] a un permanente estado embrionario de la referida ciencia". Todo intento de renuncia a un análisis sistemático implicaría un fuerte retroceso para la disciplina.

La adopción de un modelo de imputación total no supone, a priori, retrotraer a la dogmática jurídico-penal hasta el estadio previo a su nacimiento como disciplina científica. Sostener que el delito constituye un conjunto de juicios de imputación que se extienden hasta la culpabilidad no implica negar los logros realizados por la dogmática jurídico-penal, ni tornarla asistemática. Al contrario, una teoría de la imputación puede aportar criterios para dotar de contenido a algunos elementos de la teoría del delito, en especial a partir de los aportes provenientes de la lógica deóntica.

Como aspecto positivo de estos modelos teóricos, podemos mencionar el análisis lógico tomando como fundamento la teoría de las normas. Tanto HaRDWIG como HRUSCHKA construyen sus modelos a partir de las funciones que le confieren a la

44 JАКовS sostiene que se debe emprender la formulación de tipo general de imputación (Gesamtzurechnungstatbestand) que comprenda todos aquellos casos en que la interpretación de la norma incluya como culpables, hasta que su sentido delictivo esté completamente descifrado. Se trata de una totalidad, que solo puede ser cometida por una persona culpable; entonces, por una evidente falta de capacidad de culpabilidad, por ejemplo, por la conducta de un niño de diez años, ya la imputación jurídico penal se elimina mediante un reproche de lo evidente: naturaleza (JAKOBS, SsZ, cit. (n. 39): 24). 
norma penal. Ambos autores reconocen dos juicios de imputación: uno recae sobre el hecho, mientras que el otro recae sobre el sujeto. Mientras en HRUSCHKA el primer juicio de imputación comprende la atribución del hecho al sujeto como su obra, y no la valoración del mismo (su calidad de antijurídico) que lo relega a la applicatio legis adfactum, o sea al ámbito de la norma de conducta desde su dimensión retrospectiva, en HARDWIG ya el primer juicio de imputación comprende a la conducta desvalorada y ese juicio afirma que el sujeto ha realizado un hecho antijurídico, en la medida en que el deber jurídico que le alcanzaba era evitable para el sujeto. Un modelo como el propuesto por HRUSCHKA posibilita un análisis lógico del hecho delictivo a partir de la distinción entre dos sistemas de reglas. La ventaja que proporciona el sistema propuesto por este autor es la depuración del concepto de imputación: siempre que estemos valorando (interpretando) una determinada conducta, no nos encontramos en el ámbito propio de las reglas de imputación, sino en el de las reglas de conductas.

La teoría de la imputación de HARDWIG tiene una dimensión más amplia que la propuesta por HRUSCHKA, puesto que, partiendo del prototipo del delito comisivo de mera actividad, extiende, luego, las mismas reglas de imputación a la totalidad de las manifestaciones delictivas, sean comisivos u omisivos, de mera actividad o de resultado, dolosos o imprudentes. La teoría de la imputación de HRUSCHKA, por el contrario, solo es aplicable lógicamente a los casos de delitos dolosos. Para extender su aplicación a los delitos imprudentes, HRUSCHKA genera reglas de carácter adversativo que dan como resultado una imputación de carácter extraordinario, configurando al autor del delito como un agente moral responsable de su propia conducta (SILVA SÁNCHEZ, 2010: 678-679). Nuestras mayores críticas respecto de la "imputación extraordinaria" no están dirigidas al establecimiento de reglas de carácter adversativo, sino a la falta de claridad respecto del origen de las incumbencias. No resulta del todo clara su naturaleza ni cuál es su contenido específico. La importancia en torno a su determinación lo más precisa posible reside en que ellas posibiliten ampliar los márgenes de imputación y, en la medida en que sus límites no sean certeros, no solo se amplían los márgenes de imputación sino también los de la discrecionalidad. Otro punto positivo que presentan algunos de los modelos analizados es el respeto a la distinción a las dos grandes categorías del sistema. Tanto la adopción de este punto de vista de HARDWIG como el de HRUSCHKA desembocan en un modelo teórico bipartito constituido por las categorías del ilícito y de la culpabilidad. HARDWIG reconoce la posibilidad de que exista un injusto no culpable y traza entre dichas categorías la frontera entre ambos estadios de imputación ${ }^{45}$. En el caso de HRUSCHKA, el ilícito estaría compuesto por el primer estado de imputación (imputatio facti) más la valoración del hecho conforme a la norma (applicatioleggis ad factum), mientras

45 Con esta delimitación se dan las siguientes posibilidades: causación no antijurídica conforme a Derecho (en el sentido de las ciencias de la naturaleza), causación antijurídica pero no culpable (en sentido final-normativo), causación antijurídica y culpable (en sentido final-normativo), omisión antijurídica pero no culpable, omisión antijurídica y culpable (HARDWIG, 1957: 167). 
que el segundo estadio de imputación (imputatio iuris) se corresponde con la categoría de la culpabilidad.

En lo que respecta al ilícito, conforme a ambos modelos, el tipo y la antijuridicidad no componen niveles valorativos diversos, por lo que la adopción de alguna de estas teorías desemboca en un tipo total de injusto. Para estos modelos tampoco la acción constituye una categoría independiente, puesto que es a partir de la imputación que el suceso es comprendido como hecho, imputación en la que se coteja el fenómeno con la norma respecto de la cual la acción será considerada ilícita.

Bien es verdad que la teoría de la imputación de HRUSCHKA conlleva una relativización de un modelo de la teoría del delito basado en el binomio "objetivo-subjetivo". Sin embargo, de esta crítica tampoco está exenta la teoría del delito. Incluso Roxin (1970: 146) ha relativizado dicho binomio al afirmar que el sistema de la teoría del delito no se debe configurar de modo clasificatorio y categorial sino funcional. Según él, en un sistema funcional, la posición sistemática de un instituto no depende de su supuesta naturaleza, sino de su finalidad político-criminal en la cuestión de la venidera categoría sistémica.

El modelo de JAKOBS difiere de los anteriormente analizados puesto que no construye su teoría a partir de la función de determinación de la norma, sino a partir de la finalidad de la pena. La función de la norma es garantizar las expectativas normativas y la función de determinación constituye solo una función latente, un efecto secunda$\mathrm{rio}^{46}$. Un modelo teórico como el propuesto por este autor mantiene formalmente el análisis mediante categorías, pero al dotar a la acción con contenidos propios de la culpabilidad, su concepto se asemeja a los pre-científicos propios de las corrientes hegelianas, pues un concepto tan extenso pasa por alto la distinción entre capacidad de acción y capacidad de culpabilidad ${ }^{47}$. Conforme a este modo de entender la acción (Handlung), la capacidad de acción (Handlungsfähigkeit) e imputabilidad (Zurechnungsfähigkeit) se identifican; la voluntad solo alcanza la capacidad de manipularse como libre cuando el hombre comprende conscientemente la voluntad como separada de los impulsos. La capacidad de culpabilidad y la capacidad de acción son, en este sentido, idénticas (BUBNOFF, 1966: 49). El hecho del inimputable no puede, por tanto, ser contemplado como acción en sentido jurídico, en la medida en que su hecho no constituye una expresión de sentido. Todo actuar es actuar culpable, lo demás es

46 En sentido similar, LESCH (1999: 180 y ss.).

47 En igual sentido, HEgEL afirma: “como las acciones según su existencia externa, encierran en sí la accidentalidad de efectos, así también la existencia subjetiva contiene la indeterminación, la cual se refiere al poder y a la fuerza de la autoconciencia y del juicio -indeterminación que, sin embargo, puede considerarse sólo respecto a la imbecilidad, a la locura y demás cosas semejantes, así como a la edad infantil-; porque sólo tales situaciones decididas anulan el carácter del pensamiento y de la libertad volitiva y permiten no considerar el agente de acuerdo al honor de ser pensamiento y voluntad" (HeGel, Op. cit.: 231). 
mera naturaleza. Una teoría como la descrita pone en cuestión la existencia de un injusto no culpable, disolviendo la distinción entre las dos grandes categorías del sistema de la teoría del delito.

JAKOBS, a través de su concepto amplio de imputación, se acerca aún más al concepto de imputación de HeGEL, ya que esta se presenta como vinculada a la finalidad de la pena entendida en términos de prevención general positiva. Al igual que HEGEL, la teoría de la pena determina la necesidad de imputación. La pena se determina por el sinalagma indisociable entre acción y responsabilidad ${ }^{48}$. Además, la imputación se ha convertido en un juicio global sobre el hecho y el Derecho, sobre la voluntad y el conocer: tanto en JAKOBS, como en HEGEL, se trata de imputar un hecho, a la vez que se mide y se reprocha (SÁNCHEZ-Ostiz, Op. cit.: 287).

Otro punto a destacar de las denominadas teorías de la imputación es que las mismas conllevan una normativización de la dogmática jurídico-penal. El modelo de HARDWIG centrado en la infracción del deber como criterio fundamentador del ilícito; HRUSCHKA, presentado como un modelo deductivo a partir del sistema de reglas, y en el caso de JAKOBS, la normativización se produce a partir de una reconceptualización orientada a la función de prevención general positiva. Siguiendo a NEUMANN (1996: 57), podemos distinguir entre concepciones normativistas liberales (individualistas) no orientadas en consideraciones de utilidad social (utilitaristas), sino en criterios de corrección (Richtigkeit) y concepciones funcionalistas que, por el contrario, toman en cuenta una perspectiva holística ${ }^{49}$, orientando la normativización en términos consecuencialistas. Dentro de la primera de las concepciones podemos ubicar tanto a HARDWIG como a HRUSCHKA, y en la perspectiva funcionalista, a JAKOBS. La adopción de una u otra perspectiva constituye una toma de posicionamiento sobre la cual no caben objeciones. Nuestra crítica no está dirigida a la adopción de una u otra perspectiva, sino al grado de normativización que adoptan estos modelos, es decir, si los mismos siguen respetando o no un sustrato ontológico, teniendo en cuenta que la perspectiva de la imputación lleva consigo la cuestión de quién puede ser destinatario del juicio de imputación o, en otros términos, quién puede ser persona para el Derecho.

Desde nuestra postura, reconocemos un límite ontológico en el proceso de normativización desarrollado por la dogmática jurídico-penal. Las conceptualizaciones de las ciencias sociales constituyen tipificaciones de segundo orden.Las ciencias sociales, en

48 Según Hegel, el delincuente es tomado en serio como persona, lo cual significa responsabilidad por las consecuencias; es la otra cara de la moneda que supone la libertad de poder organizar (LESCH, 1995: 921).

49 Siguiendo a HoLlis, definimos como "holismo" a cualquier enfoque que tenga en cuenta a los agentes individuales (humanos o de cualquier otra clase) al apelar a algún todo mayor. El "individualismo" se refiere a cualquier versión del enfoque contrario, que tenga en cuenta las estructuras apelando a los agentes individuales (humanos o no) (Hollis, 1998: 18). 
nuestro caso el Derecho, parten de una realidad previamente interpretada y reconceptualiza dentro del marco ofrecido por conceptos de la vida cotidiana (Lebenswelt $)^{50}$.

La imputación es, de este modo, un juicio que realizan las personas en el Lebenswelt. En su vida cotidiana, las personas valoran con base en un sistema de reglas -sean estas jurídicas, morales, usos sociales, normas de utilidad, etc.-, ya sea sus propias acciones o las de otras personas, y las adscriben a su titular. La imputación constituye, de este modo, una tipificación de primer nivel, o sea, un primer nivel de abstracción a partir del cual el Derecho procederá a un nuevo proceso de abstracción. La dogmática jurídico-penal no "crea" ningún concepto de imputación, sino que reconoce esa tipificación producida en el Lebenswelt. El Derecho no parte de la nada, no construye el orden normativo a partir de una tabula rasa, sino que tiene en cuenta la realidad previamente interpretada. El acto de reconocimiento no implica de ningún modo admitir que el Derecho entienda a la imputación como la deducción que resulta de estructuras lógico-objetivas de carácter supra-normativo. La vida cotidiana solo le impone un límite respecto de lo que se entiende por imputación, límite dentro del cual la dogmática jurídico-penal goza de un amplio espectro para establecer los criterios bajo los cuales una acción puede ser imputada. Simultáneamente, reconocer el sustrato ontológico del Lebenswelt implica identificar como categorías pertenecientes a dicho sustrato al hecho desvalorado (injusto) y al juicio de reproche al sujeto agente (culpabilidad); categorías a partir de las cuales la dogmática jurídico-penal puede desarrollar su andamiaje conceptual.

Admitir que la dogmática jurídico-penal construye sus conceptos mediante un proceso de tipificación de segundo grado implica, al mismo tiempo, rechazar un normativismo radical, como el seguido por JAKOBS, quien niega toda base ontológica en la formación de los conceptos y remite para la interpretación de los mismos únicamente a las necesidades sistémicas, conduciendo de este modo a una serie de argumentaciones circulares (SCHÜNEMANN, 1995: 220-221).

50 Seguimos el concepto de Lebenswelt adoptado por ALFRED SchÜTZ, quien considera al mundo de la vida cotidiana "ingenua y pre-reflexivamente dado", no como algo "puesto entre paréntesis" sino, por el contrario, como el campo que el científico social no puede nunca abandonar, como el "hábitat natural" del problema del Verstehen. El mundo de la vida cotidiana incluye todo aquello que es dado por sabido y que normalmente no requiere reflexión, es una actitud de sentido común (BAUMAN, 2007: 168). Para ScHÜTZ (1974: 73), “Todas las explicaciones científicas del mundo social pueden, y para ciertos fines, deben referirse al sentido subjetivo de las acciones de seres humanos en los que se origina la realidad social". El Lebenswelt se constituye de este modo en el escenario y el objeto de nuestras acciones e interpretaciones (SCHÜTZ, 1973: 73). El mundo de la vida cotidiana es también, desde el principio, un mundo social cultural dentro del cual las personas se relacionan, en múltiples formas de interacción, con semejantes a quienes conocen en grados diversos de intimidad y anonimia. Y solo en él se puede constituir un entorno comunicativo común (gemeinsame kommunikative Umwelt) (SCHÜTZ, 2003: 29). 
A modo de cierre, afirmamos que en la medida en que los nuevos modelos teóricos respeten un sustrato ontológico y la necesaria distinción entre injusto y culpabilidad, la dogmática jurídico-penal no estará sufriendo un retroceso en sus conquistas logradas en cuanto disciplina científica.

\section{BIBLIOGRAFÍA}

BAUMAN, Zygmunt (2007). La hermenéutica y las ciencias sociales. VÍCTOR MAGNO Boyé (trad.). Buenos Aires: Nueva Visión.

BeCK, UlRich (1998). La sociedad del riesgo. Hacia una nueva modernidad. JoRge Navarro, Daniel Jiménez, María Rosa Borrás (trad.). Buenos Aires: Paidós.

Bourdieu, Pierre (1975). "La spécificité du champ scientifique et les conditions sociales du progrès de la raison”, en Sociologie et sociétés, vol. 7, n. . 1, pp.91-118.

BUBNOFF, EKHART (1996). Die Entwicklung des strafrechtlichen Handlungsbegriffes von Feuerbach bis Liszt unter besonderer Berücksichtigung der Hegelschule, 1. Auflage, Heidelberg, Carl Winter Universitätsverlag.

GÜNTHER, KLAUS (1994). "Individuelle Zurechnung im demokratischen Verfassungsstaat", in Jahrbuch für Recht und Ethik, ShARON BYRD, JoACHIM HruschKA, Jan. C. Joerden (comps.). Berlin: Duncker \& Humblot, Band 2, pp. 143-157.

GÜNTHER, KLAUS (2005). Schuld und kommunikative Freiheit. Studien zur personale Zurechnung strafbaren Unrechts im demokratischen Rechtstaat, 1. Auflage. Frankfurt am Main: Vittorio Klostermann.

HARDWIG, Werner (1957). Die Zurechnung. Ein Zentralproblem des Strafrechts. 1. Auflage, Hamburg: Gruyter \& Co.

HARDWIG, Werner (1968). "Verursachung und Erfolgszurechnung. Eine Anmerkung zu einer Anmerkung”, in Juristenzeitung. Tübingen, J.C.B. Mohr (Paul Siebeck).

HARDWIG, WERnER (1974). "Sittlichkeit, sittliche Normen und Rechstnormen", in Grundfragen der gesamten Strafrechtswissenchaft. Festschrift für Heinrich Henkel zum 70. Geburtstag am 12. September 1973. Claus Roxin (comp.), Berlin-New York, Walter de Gruyter.

HARDWIG, WERnER (1977). “Unrecht und Ungerechtigkeit”, in Festschrift für Eduard Dreher zum 70. Geburtstag am 29. April 1977.HANS-HEINRICH JESCHECK y HANS LÜTTGER (Comps.). Berlin-New York: Walter de Gruyter. 
Hegel, Georg Wilhelm Friedrich (2009). Grundlinien der Philosophie des Rechts oder Naturrecht und Staatswissenschaft im Grundrisse (1820/21).1 . Auflage. BERNHARD LAKEBRINK (comp.). Stuttgart: Reclam.

Hollis, Martin (1998). Filosofía de las Ciencias Sociales. Ana Lizón (trad.). Barcelona: Ariel.

HONIG, RiCHARD (1930). "Kausalität und Objektive Zurechnung”, in Festgabe für Reinhard von Frank zum 70. Geburtstag 16. August 1930. Tübingen, J.C. B. Mohr (Paul Siebeck), Band I, pp. 174-201.

HruschKa, JoAchim (1976). Strukturen der Zurechnung, 1. Auflage. Berlin-New York: Walter de Gruyter.

HRuschKa, JoACHIM (1981). "Das Strafrecht neu durchdenken! Überlegungen aus Anla $\beta$ des Buches von George P. Fletcher, Rethinking Criminal Law", in Goltdammer's Archiv für Strafrecht. PAUL-GüNTER PÖTZ (Comp.). Heidelberg, R. v. Decker's Verlag, pp. 237-250.

HRUSCHKA, JoACHIM (1984). “Ordentliche und außerondentliche Zurechnung bei Pufendorf. Zur Geschichte und zur Bedeutung der Differenz von actio libera in se und actio libera in sua causa "Zeitschrift für die gesamte Strafrechtswissenschaft. Paul Bockelmann, Karl Englisch, Wilhelm Gallas, ERnst Heinitz, Hans JoACHIM HiRsch, HANS-HeinRich Jescheck et al. (comps.), 96. Band, Berlin-New York: Walter de Gruyter, pp. 661-702.

HRUSCHKA, JOACHIM (1985). "Kann und sollte die Strafrechtswissenschaft systematisch sein?", in Juristenzeitung. HANS ERICH BRANDNER, BERHARD Grossfeld, Christian Starck, Rolf StÜrner und Ulrich Weber (comps.). Tübingen, J.C.B. Mohr (Paul Siebeck), pp. 1-10.

HRUSCHKA, JOACHIM (1988). Strafrecht nach logisch-analytischer Methode. Systematisch entwicklte Fälle mit Lösungen zum Allgemeinen Teil. 2. Auflage. Berlin-New York: Walter de Gruyer.

HRUSCHKA, JOACHIM (1991). "Verhaltensregeln und Zurechnungsregeln", in $R e$ chtstheorie. Zeitschrift für Logik, Methodenlehre, Kybernetik und Soziologie des Rechts. Karl Englisch, Hans Kelsen, Ulrich Klich und Sir Karl. R. Popper (Comps.), 22. Band, Berlin: Dunker \& Humblot, pp. 449-460.

HRUSCHKA, JOACHIM (1998). "Regreßverbot, Anstiftungsbegriff und die Konsequenzen” Zeitschrift für die gesamte Strafrechtswissenschaft. MANFRED BRUgSTALLER, Albin Eser, Hans Joachim Hirsch, Günther Jakobs, Hans-Heinrich Jescheck et al. (comps). Berlin-New York: Walter de Gruyter, 110. Band, 1998, pp. 581-610. 
HRUSCHKA, JOACHIM (2001). "Wieso ist eigentlich die, eigenschränkte Schuldtheorie 'eigenschränkt"? - Abschied von einem Meinungstreit", in Festschrift für Claus Roxin zum 70. Geburtstag am 15. Mai 2001, BERND SCHÜNEMMAN. WILFRIED BOTTKE, HANSJOACHIM RudOLPHI, HANS ACHENBACH UND BERNHARD HAFFKE (comps.). Berlin-New York: Walter de Gruyter, pp. 441-456.

HRuSchKa, JoAchim (2004). "Das deontologische Sechseck in der Jurisprudenz", in Recht der Wirtschaft und der Arbeit in Europa. Gedächtnisschrift für Wolfgang Blomeyer. Rüdiger Krause, Wilfried Veelken, Klaus Vieweg (comps.). Berlin: Dunker \& Humblot, pp. 775-788.

JakobS, GüNTHer (1976). Schüld und Prävention, 1. Auflage, Tübingen: J.C.B. Mohr (Paul Siebeck).

JAKOBS, GÜNTHER (1991). Strafrecht, Allgemeiner Teil: die Grundlagen und die Zurechnungslehere. Lehrbuch. 2. Neubearbeitete und erweitete Auflage. Berlin-New York: Walter de Gruyter.

JAKOBS, GÜNTHER (1995). "Das Strafrecht zwischen Funktionalismus und, Alteuropäischem“ Prinzipiendenken. Oder: verabschiedung des, alteuropäischen' Strafrechts?", in Zeitschrift für die gesamte Strafrechtswissenschaft.MANFRED BURGSTALLER, Albin Eser, Ernst Heinitz, Hans Joachim Hirsch et al. (comps.). Berlin-New York: Warter de Gruyter, 107. Band, pp. 843-876.

JAKOBS, GÜNTHER (1997). "El concepto jurídico-penal de acción”, en Estudios de Derecho penal. Manuel Cancio Meliá (trad.). Madrid: Civitas, pp. 101-125.

JAKOBS, GÜNTHER (1997). "El principio de culpabilidad", en Estudios de Derecho penal. Manuel Cancio Meliá (trad.). Madrid: Civitas, pp. 365-393.

JAKOBS, GÜNTHER (1999). Norm, Person und Gesellschaft: Vorüberlegungen zu einer Rechtsphilosophie. 2. Auflage, Berlin: Duncker \& Humboldt.

JAKOBS, GÜNTHER (2003). “¿Qué protege el Derecho penal: bienes jurídicos o la vigencia de la norma?”, en El funcionalismo en Derecho penal. Libro homenaje a Günther Jakobs. Eduardo Montealegre Lynett (coord.), Manuel CAncio Meliá (trad.): Bogotá: Universidad Externado de Colombia, pp. 39-56.

JAKOBS, GÜNTHER (2003). "El principio de Culpabilidad”, en El principio de Culpabilidad. Dos cuestiones fundamentales. Manuel Cancio Meliá (trad.). Bogotá: Universidad Externado de Colombia.

JAKOBS, GÜNTHER (2004). Sobre la normativización de la dogmática jurídico-penal. Manuel Cancio Meliá (trad.). Bogotá: Universidad Externado de Colombia. 
JAKOBS, GÜNTHER (2004a). "Imputación jurídico-penal, desarrollo del sistema con base en las condiciones de la vigencia de la norma”, en Dogmática de Derecho penal y la configuración normativa. JAVIER SÁNCHEZ-VERA GÓMEZ-TrELlES (trad.), Madrid: Civitas.

JAKOBS, Günther (2012). System der strafrechtlichen Zurechnung. 1. Auslage, Frankfurt am Main, Vittorio Klostermann.

Kelsen, Hans (1943). Society and Nature. A sociological Inquiry. London, Chicago: University Press.

Kelsen, Hans (1960). Reine Rechtslehre. 2. Auflage, Wien, Franz Deuticke.

LARENZ, KARL (1974). Methodenlehre der Rechstwissenschaft. 4. Ergänzte Auflage, Berlin-Heidelberg-New York: Springer.

LATOUR, BRUnO (1991). Nunca fuimos modernos. Ensayo de antropología simétrica. Víctor GoldsteIn (trad.). Buenos Aires: Siglo XXI, 2007.

LESCH, HeIKo (1995). "Intervención delictiva e imputación objetiva", en ADPCP, T.XLVIII, Fasc. III, septiembre-diciembre 1995, pp. 911-972.

LESCH, HeIKO (1999). Der Verbrechensbegriff: Grundlienien einer funktionalen Revision.1. Auslage, Köln-Berlin-Bonn-München: Carl Heymanns.

LóPez Díaz, Claudia (2006). Acciones a propio riesgo. Exclusión de la tipicidad por responsabilidad de la víctima con base en una concepción funcional estructural de la sociedad. Bogotá: Universidad Externado de Colombia.

Mir Puig, SAntiago (2003). Introducción a las bases del Derecho penal: concepto y método. Buenos Aires: B de F.

Neumann, Ulfrid (1985). "Normtheorie und strafrechtliche Zurechnung “Goltdammer's Archiv für Strafrecht. PAUL-GÜNTER PÖTZ (comp.). Heidelberg, R. v. Decker's Verlag, pp. 389-401.

Neumann, Ulfrid (1987). "Neue Entwicklugen im Bereich der Argumentationsmunster zum Begründung oder zum Ausschluß strafrechlicher Verantwortlichkeit" Zeitschrift für die gesamte Strafrechtswissenschaft. PAUL BOCKELMANN, KARL Englisch, Wilhelm Gallas, ERnst Heinitz, Hans Joachim Hirsch et al. (comps.), Berlin-New York, Walter de Gruyter, 99. Band, pp. 582-583. 
NeUmann, Ulfrid (1996). "Vom normativen zum funktionalen Strafrechtsverständnis", in Perspektiven der Strafrechtsentwicklung. 1. Auflage, HeIKE Jung, HeInZ MÜLLERDietZ, Ulfrid NeumanN (Comps.), Baden-Baden, Nomos, pp. 57-78.

Pawlik, Michael (2007). "Strafrechtswissenschaftstheorie", in Festschrift für Günther Jakobs zum 70. Geburtstag am 26. Juli 2007.Michael PAWLiK, RAINER ZACZYK (comps.). Berlin: Carl Heymanns, pp. 469-495.

REINHOLD, JOACHIM (2009). Unrechtszurechnung und der Abbruch rettender Verläufe, 1. Auflage, Tübingen, Mohr Siebeck.

Roxin, Claus (1970). “Gedanken zur Problematik der Zurechnung im Strafrecht”, in Festscrhift für Richard M. Honig zum 80. Geburtstag 3. Januar 1970. Herausgegeben von der Juristischen Fakultät der Georg-August-Universität Göttingen, Göttingen, Otto Schwatz \& Co., pp. 133-150.

SánChez-Ostiz, PABlo (2008). Imputación y teoría del delito. La teoría kantiana de la imputación y su recepción en el pensamiento jurídico-penal contemporáneo. Buenos Aires: B de F.

SCHÜNEMANN, BERND (2012). "Introducción al razonamiento sistemático en Derecho penal", en El sistema moderno del Derecho penal. Cuestiones fundamentales. JESÚsMaría Silva SÁncheZ (trad.), 2a ed. Buenos Aires: B de F, pp. 1-77

SCHÜNEMANN, BERND (1995). "Kritische Ammerkungen zur geistigen Situation der deutschen Strafrechtswissenschaft", in Goltdammer's Archiv für Strafrecht.PAULGÜNTER PöTZ (Comp.), Heidelberg, R. v. Decker's Verlag, pp. 201-229

SCHÜNEMANN, BERND (2001). "Strafrechtsdogmatik als Wissenschaft", in Festschrift für Claus Roxin zum 70. Geburtstag am 15. Mai 2001.BERND SCHÜNEMMAN. WILFRIED Bottke, Hans-Joachim Rudolphi, Hans Achenbach, Bernhard HaffKe(Comps.), Berlin-New York, Walter de Gruyter, pp. 1-32.

Silva SÁnchez, Jesús-María (2003). Normas y acciones en Derecho penal. Buenos Aires: Hammurabi.

Silva SÁnchez, Jesús-María (2006). La expansión del Derecho penal. Aspectos de la Política criminal en las sociedades postindustriales. Buenos Aires: B de F.

SChÜTZ, Alfred (1973). On Phenomenology and Social Relations, Helmut W AGNER (ed.). Chicago: Chicago University Press.

SChÜTZ, Alfred (1974). El problema de la realidad social: Escritos I, MAURICE NATANSON (comp.). Buenos Aires: Amorrortu. 
Schütz, Alfred, Luckmann, Thomas (2003).Strukturen der Lebenswelt, 1. Auflage, Konstanz, C.H. Beck.

Schütz, Alfred; Luckmann, Thomas (2010). Aproximación al Derecho penal Contemporáneo. 2. ${ }^{\mathrm{a}}$ ed., Buenos Aires: B de F.

WALlERSTEIn, IMMANUEL (coord.) (1996). Abrir las ciencias sociales. Informe de la Comisión Gulbenkian para la reestructuración de las ciencias sociales. Ciudad de México: Siglo XXI.

WALlerstein, IMMANUEl (2005). Las incertidumbres del saber. JUliETA BARBA, SilviA JAWERBAUM (trad.). Barcelona: Gedisa.

WINCH, PETER (2003). The Idea of a Social Science and its Relation to Philosophy. $2^{\mathrm{a}}$ ed. London: Routledge.

Wolter, Jürgen (1996). “Zur Dogmatik und Rangfolge von materiellen Ausschlußgründen, Verfahrenseinstellung, Absehen und Mildern von Strafe: Strukturen eines ganzheitlichen Straftat-, Strafprozeß- und Strafzusummessungssystems", in Straftat, Strafzumessung und Strafprozeß im gesamten Strafrechtssystem: Straftatbegriff-Straftatzurechnung - Strafrechtszweck - Strafausschluß-Strafverzicht-Strafklagverzicht. Jürgen Wolter, GeORg Freund (eds.). Heidelberg, C.F.: Müller Vertrag, pp. 1-42. 
